\title{
Resistencia química del hormigón XX. Acción del agua de mar: influencia de la adición de escoria a un cemento portland. Estudio por DRX
}

DEMETRIO GASPAR-TEBAR y JOSE LUIS SAGRERA-MORENO Drs. en Ciencias Quimicas (IETCC/CSIC)

\section{$R E S U M E N$}

En el presente trabajo, continuación de otros, se estudia por DRX la evolución de las caracteristicas estructurales de la fracción enriquecida (cemento hidratado-atacado) extraida de uno de los prismas de mortero $(1: 3)$ de $1 \times 1 \times 6 \mathrm{~cm}$ de las diversas series de probetas fabricadas con un cemento portland (cemento 3) it con las mezclas cemento 3/escoria $=85 / 15,65 / 35,40 / 60 \because 30 / 70$, en peso, sumergidas en agua de mar artificial (ASTM D 1141-75) durante 56,90,180y360 dias -en esta etapa- después del periodo de curado (24 horas en un recinto saturado de humedad y hasta 22 dias bajo agua potable filtrada). Asi mismo, se estudia por DRX la composición estructural de las nuevas fases sólidas formadas en los medios de conservación-ataque (agua de mar artificial) en donde han estado sumergidas las probetas de mortero.

En los $D R X$ de las diversas fracciones enriquecidas se han identificado, con intensidad variable, los picos de la brucita, ettringita y calcita, en todos ellos, y' los de la sal de Friedel, yeso y portlandita, en parte. La intensidad de dichos picos depende de la mezcla utilizada en la fabricación de las probetas de mortero y' del tiempo de conservación-ataque.

En los DRX de las nuevas fases sólidas se han detectado los picos de la calcita y' del aragonito con intensidad variable, predominando los de una forma sobre los de la otra según las condiciones del sistema y de un modo especial de la mezcla cemento 3/escoria empleada en la elaboración de las probetas de mortero; además, se han identificado los picos de la brucita en los diagramas de las fases sólidas correspondientes a los medios en donde han estado sumergidas las probetas de mortero hechas con cemento 3 y con la mezcla que tiene el $15 \%$ de escoria.

\section{$S U M M A R Y$}

In this work, which is a follow-up of others, the evolution of structural features of enriched fraction (attacked-hydrated cement) is studied by DRX, extracted from one of the mortar prims ( $1: 3)$ of $1 \times 1 \times 6 \mathrm{~cm}$ of the various series of test specimens made with a portland cement (cement 3 ) and mixtures cement 3/slag $=85 / 15,65 / 35,40 / 60$ and 30/70, in weight, immersed in artificial sea water (ASTM D 1141-75) for 56, 90, 180 and 360 days -at this stage- following curing period ( 24 hours in humidity saturated enclosure and up to 22 days under filtered drinking water). In addition, structural composition was studied by' DRX of the new solid phases formed in the preservation-attack media (artificial sea water) where the mortar test pieces were immersed.

In the DRX of the various enriched fractions, the peaks of brucite, ettringite and calcite were identified with variable intensity in them all, and those of Friedel salt, plaster and portlandite in part. Intensity of these peaks depends on the mixture used for making the mortar test pieces and on the preservation-attack time.

In the DRX of the new' solid phases, the peaks of calcite and aragonite were detected with variable intensity, and those of one form prevailed over those of another, depending on system conditions and particularly, on the cemen 3/slag mixture used to elaborate the mortar test pieces; the brucite peaks were in addition identified in the diagrams of the solid phases corresponding to media where the mortar test pieces made with cement 3 and the mixture which has $15 \%$ slag were immersed.

\section{INTRODUCCION}

En otros trabajos anteriores se estudió, por una parte, la evolución que experimenta la resistencia quimica por el método de Koch-Steinegger y las modificaciones sufridas por las 
resistencias mecánicas a' flexotracción de las probetas de mortero (1:3) de $1 \times 1 \times 6 \mathrm{~cm}$ hechas con el cemento portland (cemento $3<>$ P-450), objeto del presente articulo, y con las mezclas cemento $3 /$ escoria $=85 / 15-65 / 35-40 / 60$ y $30 / 70$, en peso, sumergidas en agua potable filtrada $(*)$, unas series de 12 probetas, y en agua de mar artificial (ASTM D1 141-75) (**), otras series análogas, durante 56-90-180 y 360 días después de haberlas curado 24 horas en un recinto saturado de humedad y, a continuación, bajo agua potable filtrada durante 21 días (1) $\mathrm{y}$, por otra parte, la composición estructural de las nuevas fases sólidas formadas en los medios de curado y de conservación (agua potable filtrada) en donde han estado sumergidas las mencionadas probetas de mortero, asi como la evolución de las fases cristalinas de la fracción enriquecida (cemento hidratado) extraída de uno de los prismas de cada serie de probetas de mortero correspondiente al sistema cemento 3/escoria-agua potable filtrada (2).

En el presente trabajo, continuación de los anteriores (1) (2) y que se ampliará con otros, se estudia por DRX la composición estructural de la nueva fase sólida formada en el medio de conservación-ataque (agua de mar artificial), así como la evolución de las características estructurales de los compuestos cristalinos de la fracción enriquecida, cemento hidratado-atacado, extraida de uno de los prismas de mortero de cada serie del sistema cemento 3/escoria-agua de mar artificial.

\section{PARTE EXPERIMENTAL}

Con el fin de conocer las modificaciones estructurales que han sufrido los compuestos cristalinos del cemento 3 hidratado y de las mezclas hidratadas cemento 3/escoria $=85 / 15-65 / 35-40 / 60$ y 30/70 (en peso), sometidos a la acción del agua de mar artificial (ASTM D1141-75) durante 56 - 90 - 180 y 360 dias, asi como la composición estructural de la nueva fase sólida formada en dicha agua de mar en donde han estado sumergidas las probetas de mortero, se ha realizado el estudio por difracción de rayos $\mathrm{X}$ de la fracción enriquecida extraída de una de las probetas de mortero de cada una de las series del sistema cemento 3/escoria-agua de mar artificial y de las correspondientes fases sólidas.

De los materiales utilizados y características (cemento 3 y escoria, arena, agua de mar artificial y agua potable filtrada), de la técnica operatoria seguida para preparar las mezclas cemento 3/escoria, así como para curar y conservar las probetas de mortero de las diversas series en agua de mar artificial, se dió cuenta en (1).

La preparación de la nueva fase sólida formada en el agua de mar artificial en donde han estado sumergidas las probetas de mortero durante 56-90-180 y 360 días, así como de la fracción enriquecida extraida de uno de los prismas de mortero de las distintas series de probetas de mortero, se indica en (3).

Los diagramas de difracción por rayos $\mathrm{X}$ de la nueva fase sólida $\mathrm{y}$ de las fracciones enriquecidas se han obtenido por medio de un equipo Philips PW-1010, con una unidad de registro PW-1540, trabajando en las condiciones reseñadas en (4).

\section{RESULTADOS Y DISCUSION}

Sistema: cemento 3/escoria-agua de mar artificial

\subsection{Estudio de la fase sólida formada}

En los diagramas de difracción de rayos $X$ (figuras 1 a 5) de la fase sólida formada en el agua

(*) Sistema: cemento 3/escoria-agua potable filtrada. 

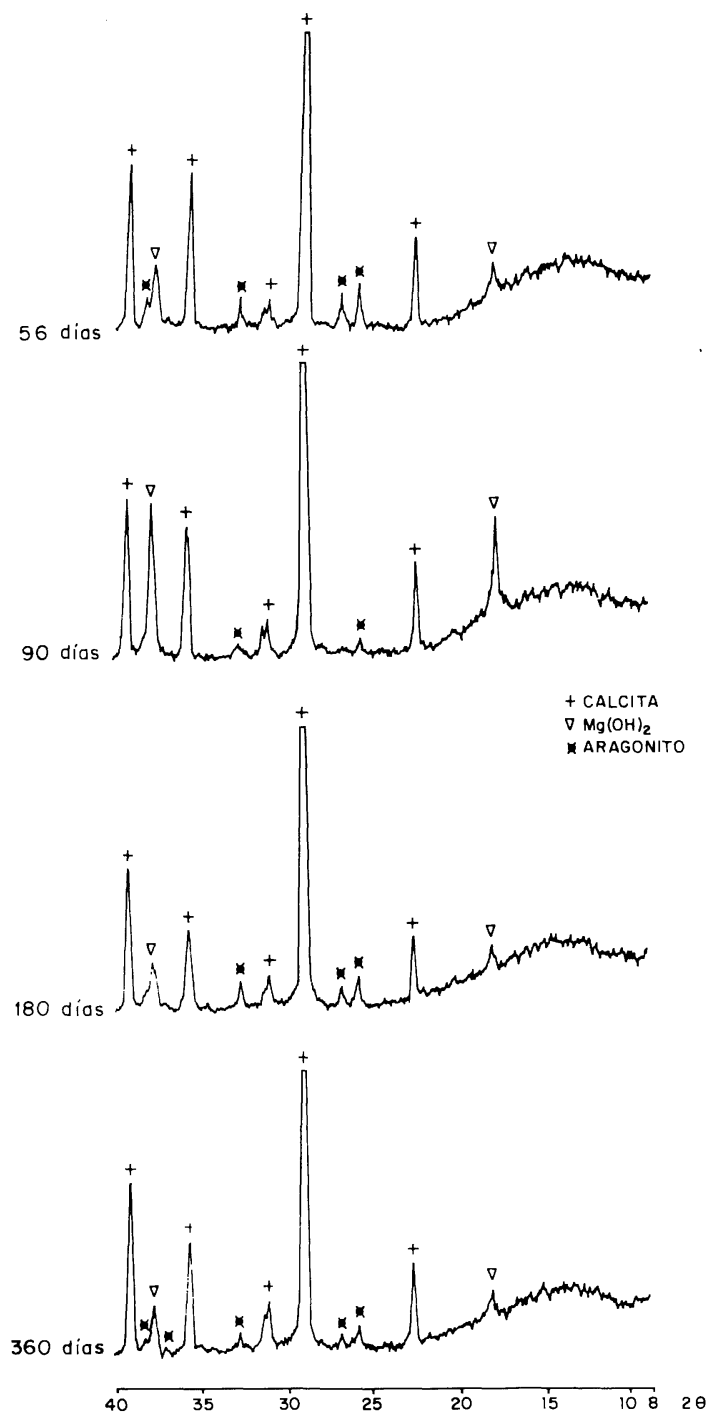

Fig. 1.-Sistema: cemento 3/escoria-agua de mar artificial.

Mezcla: cemento $3 /$ escoria $=100 / 0$ (en peso). DRX de la fase sólida.
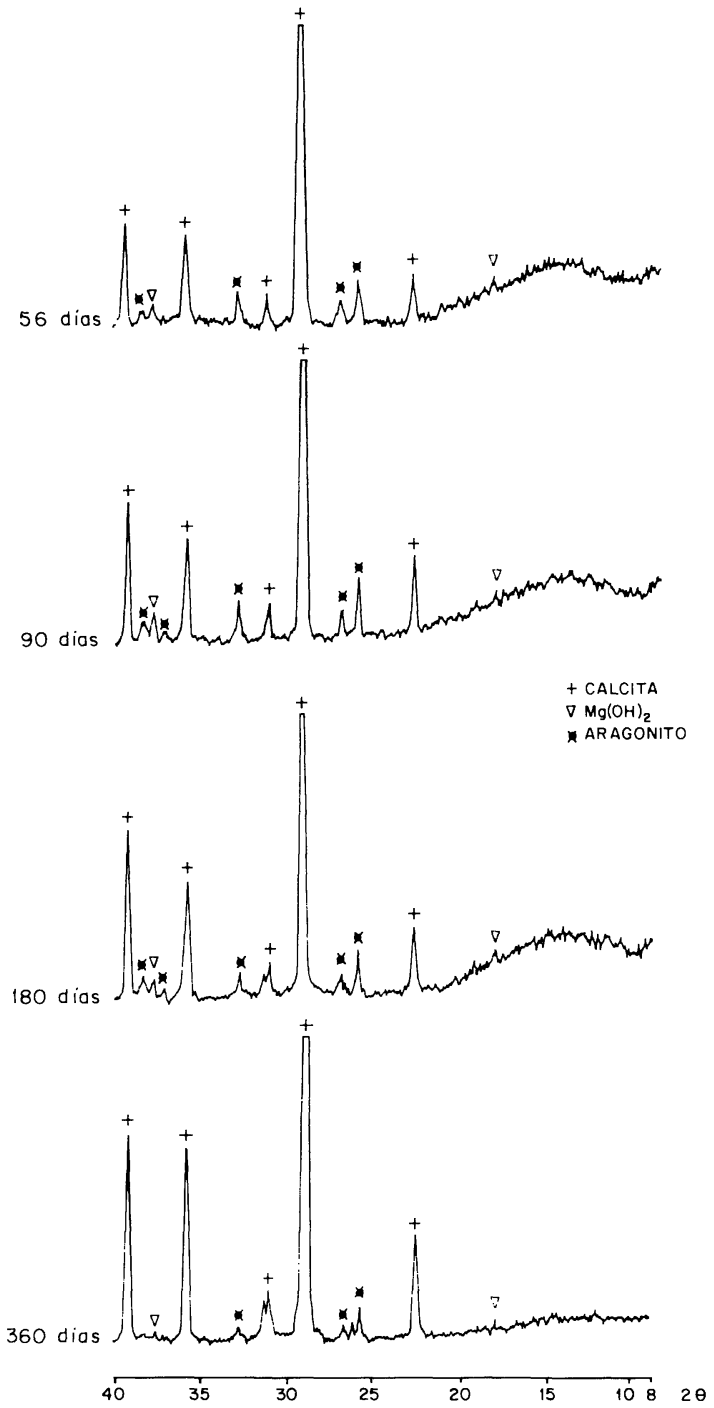

Fig. 2.-Sistema: cemento 3/escoria-agua de mar artificial. Mezcla: cemento $3 /$ escoria $=85 / 15$ (cn peso). DRX de la fase sólida.

de mar artificial (ASTM D1141-75) en donde han estado sumergidas las probetas de mortero ( $1: 3$ ) de las distintas series, durante el periodo de conservación-ataque (56 - 90 - 180 y 360 días), se han identificado los picos de los siguientes compuestos cristalinos: brucita $\left[\mathrm{Mg}(\mathrm{OH})_{2}\right]$, calcita $\left[\mathrm{CaCO}_{3}\right]$ y aragonito $\left[\mathrm{CaCO}_{3}\right]$.

La nueva fase sólida se encuentra, en ciertos casos, impurificada por pequeñas fracciones desprendidas de las probetas de mortero.

En la tabla 1 se incluyen las intensidades relativas de uno de los picos característicos de los compuestos cristalinos identificados: $2 \theta=18,4^{\circ}$ para la brucita; $26,2^{\circ}$ para el aragonito y $29,5^{\circ}$ para la calcita.

Los picos de la calcita, con intensidad variable, se han detectado en los DRX de las muestras de las distintas fases sólidas formadas en el agua de mar artificial, en donde han estado sumergidas las diversas series de probetas durante las cuatro edades estudiadas.

La máxima intensidad de los picos de la calcita, muy parecida en los DRX de las cuatro edades, corresponde a la fase sólida formada en los medios de conservación-ataque (agua de mar 

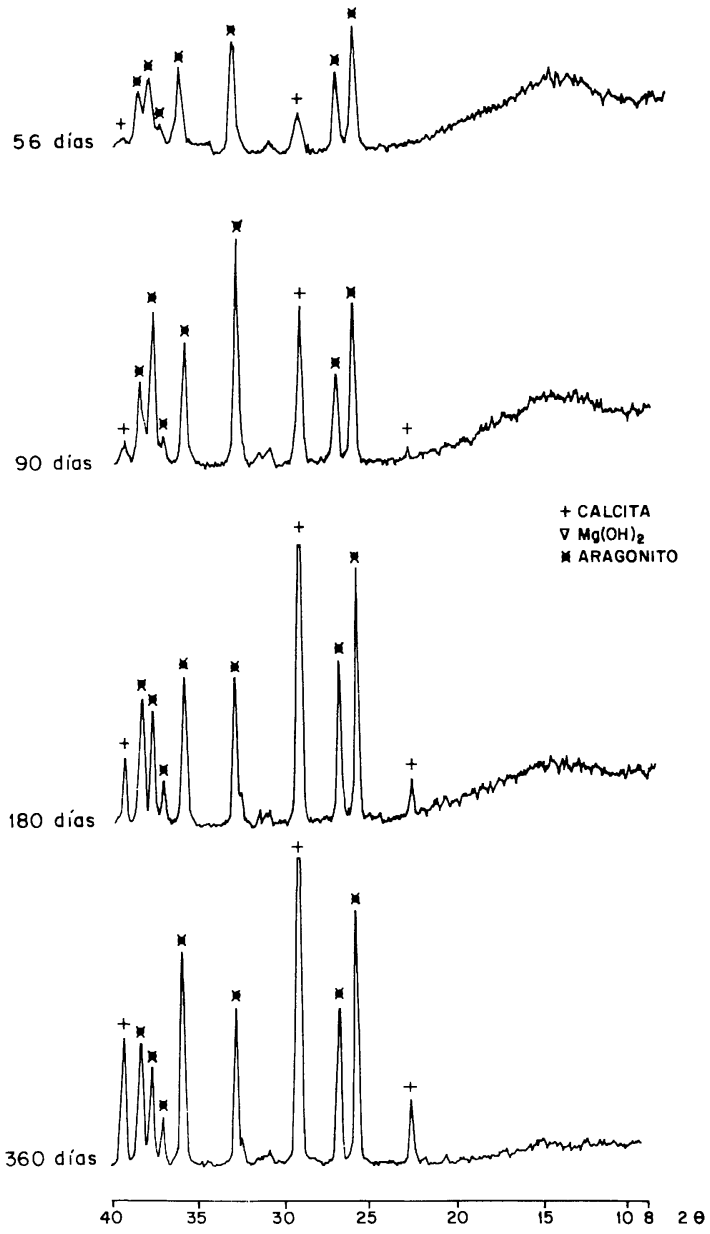

Fig. 3.-Sistema: cemento 3/escoria-agua de mar artificial. Mezcla: cemento $3 /$ escoria $=65 / 35$ (en peso) . DRX de la fase sólida.
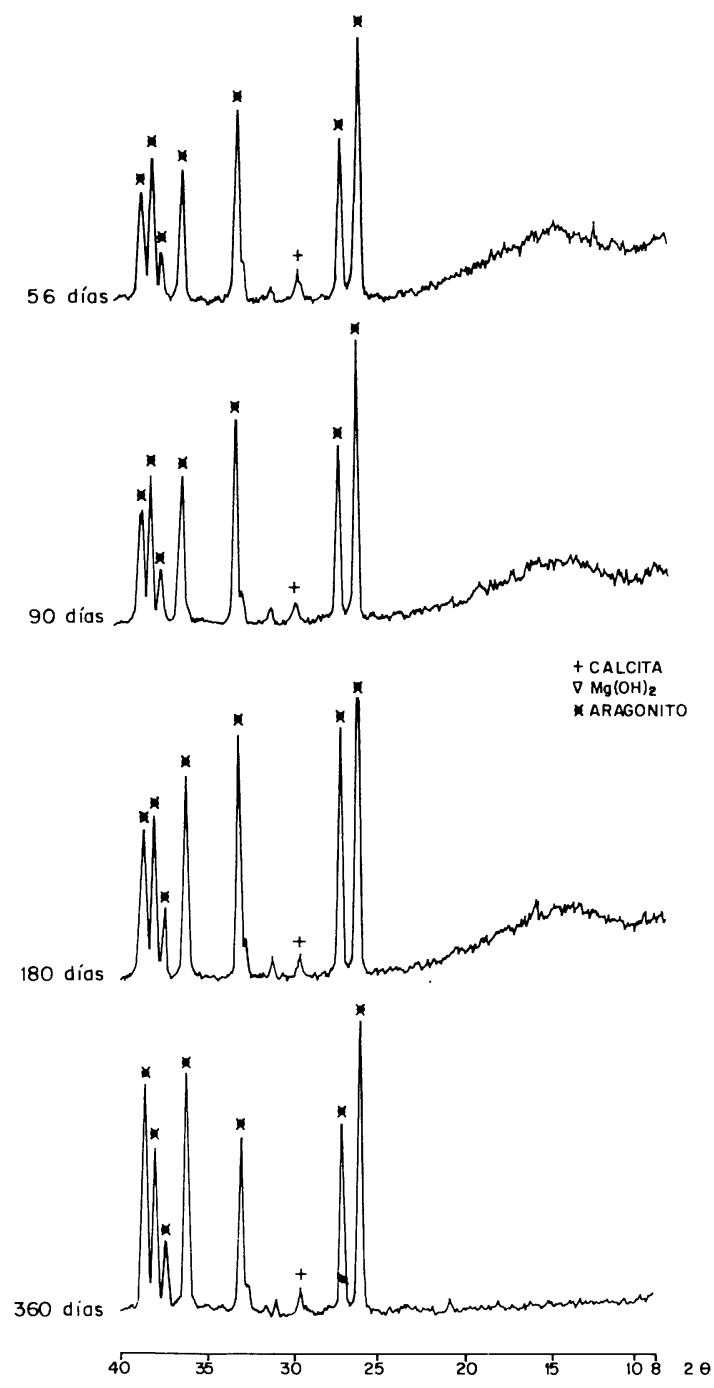

Fig. 4.-Sistema: cemento 3/escoria-agua de mar artificial. Mezcla: cemento $3 /$ escoria $=40 / 60$ (en peso). DRX de la fase sólida.

T A B LA 1

Sistema: cemento 3/escoria-agua de mar artificial

Diagramas de difracción de rayos $X$ de la fase sólida formada.

Intensidad relativa de uno de los picos característicos

\begin{tabular}{|c|c|c|c|c|c|c|c|c|c|c|c|c|}
\hline \multirow{2}{*}{$\begin{array}{c}\text { Cemento } 3 / \text { escoria } \\
\text { en peso }\end{array}$} & \multicolumn{3}{|c|}{56 días } & \multicolumn{3}{|c|}{90 dias } & \multicolumn{3}{|c|}{180 dias } & \multicolumn{3}{|c|}{360 días } \\
\hline & B & Ag & Ce & B & $\mathbf{A g}$ & Ce & B & Ag & Cc & B & Ag & Ce \\
\hline $100 / 0$ & 2 & 2 & 24 & 6 & + & 24 & 2 & 2 & 24 & 2 & 2 & 24 \\
\hline $85 / 15$ & + & 3 & 24 & + & 4 & 24 & + & 3 & 24 & + & 1 & 24 \\
\hline $65 / 35$ & - & 8 & 3 & - & 9 & 9 & - & 16 & 20 & - & 15 & 22 \\
\hline $40 / 60$ & - & 15 & 2 & - & 17 & 1 & - & 18 & 1 & - & 18 & 1 \\
\hline $30 / 70$ & - & 20 & 1 & - & 16 & 1 & - & 20 & 2 & - & 18 & 3 \\
\hline
\end{tabular}

$\mathrm{B}=$ Brucita $. \quad \mathrm{Ag}=$ Aragonito. $\quad \mathrm{Cc}=$ Calcita $. \quad-=$ No detectado $. \quad+=$ Detectado. 

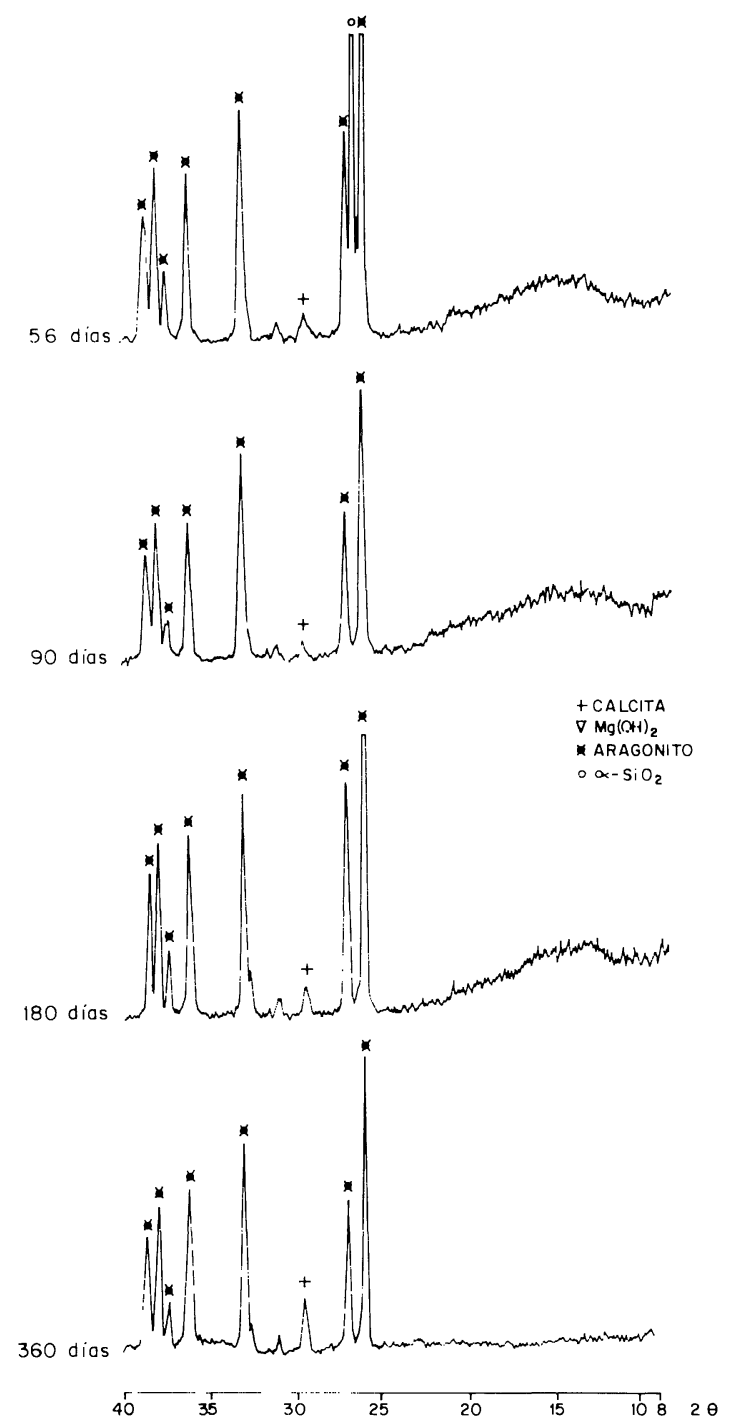

Fig. 5.-Sistema: cemento 3/escoria-agua de mar artificial.

Mezcla: cemento $3 /$ escoria $=30 / 70($ en peso). DRX de la fase solida.

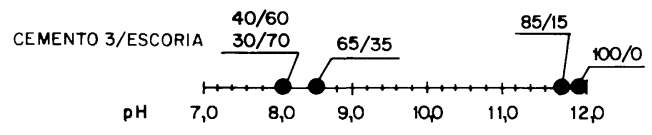

CEMENTO/ESCORIA

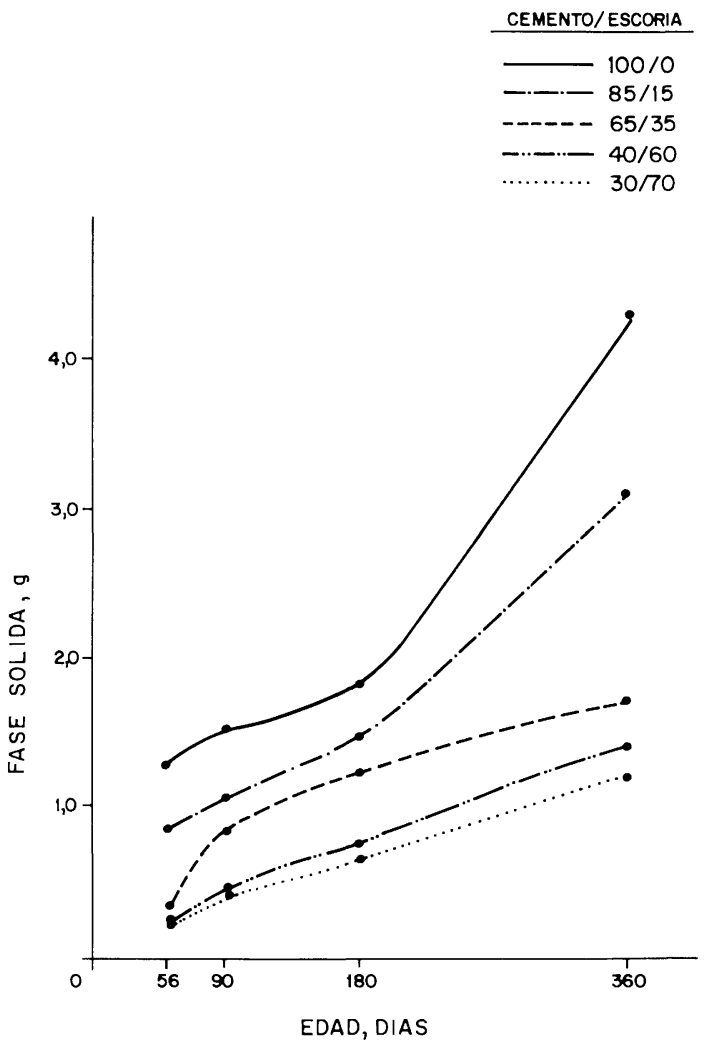

Fig. 6.-Sistema: cemento 3/escoria-agua de mar artificial. Evolución de la cantidad de fase sólida y del PH.

artificial) de las series de probetas hechas con cemento 3 y con la mezcla que tiene el $15 \%$ de escoria (en peso) y la mínima intensidad, para cada edad, se presenta en los diagramas de la fase sólida que aparece en el agua de mar artificial en donde han estado sumergidas las probetas hechas con las dos mezclas que tienen el mayor contenido de escoria (60 y $70 \%$, en peso).

Los picos del aragonito, que también se han identificado en los diagramas de difracción de rayos $\mathrm{X}$ de las muestras de las diversas fases sólidas, presentan la minima intensidad para cada edad en los DRX de las fases sólidas formadas en el agua de mar artificial, en donde han estado sumergidas las series de probetas hechas con cemento 3 y con la mezcla que tiene el menor contenido de escoria (15\%). y la máxima intensidad en los diagramas de las fases sólidas que aparecen en los medios en donde han estado las series de probetas hechas con las dos mezclas que tienen los mayores contenidos de escoria (60) y $70 \%)$.

En los DRX de las fases solidas que se han obtenido en el agua de mar, en donde se han sumergido las series de probetas confeccionadas con la mezcla cemento $3 /$ escoria $=65 / 35$ (en peso). la intensidad de los picos del aragonito es mayor que la de los picos de la calcita en la primera edad, del mismo orden en la segunda y menor en las dos edades restantes. 
Los picos de la brucita se han puesto de manifiesto en los DRX de las fases sólidas que aparecen en los medios en donde han estado sumergidas las series de probetas de mortero hechas con cemento $3 \sin$ adición de escoria y con la mezcla cemento $3 /$ escoria $=85 / 15$, en peso.

En la figura 6, se ha representado la cantidad de fase sólida formada, en gramos, en función del tiempo de conservación-ataque, de cada una de las series de probetas de mortero estudiadas, en donde puede observarse que la cantidad de dicha nueva fase sólida formada en el agua de mar artificial en donde han estado sumergidas las mencionadas series, es:

a) función de la mezcla utilizada en la fabricación de las probetas de mortero, disminuyendo, para cada edad, conforme aumenta la cantidad de escoria en la mezcla o, lo que es lo mismo, disminuye la de clínker utilizada para fabricar las probetas.

b) función del tiempo de conservación-ataque para cada mezcla. Dicha fase sólida aumenta conforme lo hace el tiempo de conservación-ataque.

Así mismo, en la mencionada figura 6 se señalan los valores más frecuentes del $\mathrm{pH}$ de los medios de conservación-ataque, para los distintos casos estudiados, una vez extraidas las probetas de mortero. El pH del agua de mar $(6,5)$ ha experimentado un incremento en todos los casos, encontrándose comprendido en los entornos 11,8 a 12,5 - 11,7 a 12,0 - 7,5 a 10,0 - 7,7 a 8,5 para las mezclas cemento $3 /$ escoria $=100,0$ (en peso) el primero, $85 / 15$ (en peso) el segundo, 65/35 (en peso) el tercero y $40 / 60$ y 30/70 (en peso), el cuarto.

\subsection{Estudio de la fracción enriquecida}

En los diagramas de difracción de rayos $\mathrm{X}$ (figuras 7 a 11), que corresponden a las fracciones enriquecidas extraidas de una de las probetas de mortero de las distintas series hechas con cemento 3 (figura 7) y con las mezclas cemento $3 /$ escoria $=85 / 15$ (figura 8) 65/35 (figura 9) - 40/60 (figura 10) y 30/70 (figura 11), en peso, sumergidas después del periodo de curado en agua potable filtrada $(1+21$ dias) o en agua de mar artificial (ASTM D1141-75) durante los diversos períodos de conservación-ataque (56, 90, 180 y 360 días), se han identificado los picos de los siguientes compuestos cristalinos: ettringita $\left[3 \mathrm{CaO} \cdot \mathrm{Al}_{2} \mathrm{O}_{3}\right.$. $\left..3 \mathrm{CaSO}_{4} \cdot 31 \mathrm{H}_{2} \mathrm{O}\right]$, sal de Friedel $\left[3 \mathrm{CaO} \cdot \mathrm{Al}_{2} \mathrm{O}_{3} \cdot \mathrm{CaCl}_{2} \cdot 10 \mathrm{H}_{2} \mathrm{O}\right.$ ], yeso [ $\mathrm{CaSO}_{4} \cdot 2 \mathrm{H}_{2} \mathrm{O}$ ], portlandita $\left[\mathrm{Ca}(\mathrm{OH})_{2}\right]$, brucita $\left[\mathrm{Mg}(\mathrm{OH})_{2}\right]$ y calcita $\left[\mathrm{CaCO}_{3}\right]$, además de $\alpha-\mathrm{SiO}_{2}$ que procede de la arena utilizada en la fabricación de las probetas de mortero, presentando las modificaciones que se señalan en los apartados siguientes.

En las tablas 2 a 7 se incluyen las intensidades relativas de uno de los picos característicos de los compuestos cristalinos identificados: $2 \theta=9,1^{\circ}$ para la ettringita (tabla 2 ); $11,2^{\circ}$ para la sal de Friedel (tabla 3 ); $11,7^{\circ}$ para el yeso (tabla 4$) ; 18,0^{\circ}$ para la portlandita (tabla 5 ); $18,4^{\circ}$ para la brucita (tabla 6 ) y $29,5^{\circ}$ para la calcita (tabla 7 ).

En dichas tablas y dentro de paréntesis figuran las intensidades relativas de los compuestos cristalinos correspondientes al sistema cemento 3/escoria-agua potable filtrada, tomados de (2).

\section{a) Influencia del tiempo de conservación-ataque para las probetas hechas con una mezcla}

La intensidad de los picos de los diagramas de difracción de rayos $\mathrm{X}$ de las fracciones enriquecidas de las distintas series de probetas fabricadas con una misma mezcla es función, por regla general, del tiempo de conservación-ataque (tablas 2 a 7), como se aprecia a continuación:

- mezcla: cemento $3 /$ escoria $=100 / 0$, en peso, $($ figura 7$)$

- Ettringita: Los picos de este compuesto se han detectado en todos los DRX; su intensidad es 
TABLA 2

Sistema: cemento 3/escoria-agua de mar artificial

Ettringita: diagramas de difracción de rayos $X$.

Intensidad relativa de uno de los picos característicos

\begin{tabular}{|c|c|c|c|c|}
\hline \multirow{2}{*}{$\begin{array}{c}\text { Cemento 3/escoria } \\
\text { en peso }\end{array}$} & \multicolumn{4}{|c|}{ Edad, dias } \\
\cline { 2 - 5 } & $\mathbf{2 2 + 5 6}$ & $\mathbf{2 2 + 9 0}$ & $\mathbf{2 2 + 1 8 0}$ & $22+\mathbf{3 6 0}$ \\
\hline $100 / 0$ & $6(4)$ & $5(2)$ & $6(2)$ & $8(4)$ \\
$85 / 15$ & $5(4)$ & $3(2)$ & $5(2)$ & $7(4)$ \\
$65 / 35$ & $4(3)$ & $4(1)$ & $4(1)$ & $5(4)$ \\
$40 / 60$ & $2(2)$ & $4(2)$ & $2(+)$ & $3(2)$ \\
$30 / 70$ & $3(2)$ & $3(2)$ & $3(2)$ & $3(1)$ \\
\hline
\end{tabular}

$+=$ Detectado

T A B L A 3

Sistema: cemento 3/escoria-agua de mar artificial Sal de Friedel: diagramas de difracción de rayos $X$.

Intensidad relativa de uno de los picos característicos

\begin{tabular}{|c|c|c|c|c|}
\hline \multirow{2}{*}{$\begin{array}{c}\text { Cemento 3/escoria } \\
\text { en peso }\end{array}$} & \multicolumn{5}{|c|}{ Edad, dias } \\
\cline { 2 - 5 } & $\mathbf{2 2 + 5 6}$ & $\mathbf{2 2 + 9 0}$ & $\mathbf{2 2 + 1 8 0}$ & $\mathbf{2 2 + 3 6 0}$ \\
\hline $100 / 0$ & - & - & - & - \\
$85 / 15$ & 2 & 4 & 1 & 3 \\
$65 / 35$ & 5 & 5 & 3 & 4 \\
$40 / 60$ & 4 & 5 & 3 & 3 \\
$30 / 70$ & 3 & 4 & 3 & 3 \\
\hline
\end{tabular}

$-=$ No detectado. $\quad+=$ Detectado.

T A B LA 4

Sistema: cemento 3/escoria-agua de mar artificial

Yeso: diagramas de difracción de rayos $X$.

Intensidad relativa de uno de los picos característicos

\begin{tabular}{|c|c|c|c|r|}
\hline \multirow{2}{*}{$\begin{array}{c}\text { Cemento 3/escoria } \\
\text { en peso }\end{array}$} & \multicolumn{4}{|c|}{ Edad, dias } \\
\cline { 2 - 5 } & $\mathbf{2 2 + 5 6}$ & $\mathbf{2 2 + 9 0}$ & $\mathbf{2 2 + 1 8 0}$ & $\mathbf{2 2 + 3 6 0}$ \\
\hline $100 / 0$ & $1(1)$ & $+(+)$ & $-(1)$ & $-(1)$ \\
$85 / 15$ & $-(1)$ & $-(1)$ & $-(1)$ & $-(1)$ \\
$65 / 35$ & $1(1)$ & $-(-)$ & $1(-)$ & $-(+)$ \\
$40 / 60$ & $-(1)$ & $2(+)$ & $-(+)$ & $-(1)$ \\
$30 / 70$ & $-(+)$ & $3(+)$ & $-(-)$ & $-(-)$ \\
\hline
\end{tabular}

$-=$ No detectado. $\quad+=$ Detectado.

MAteriales de Construccion N. ${ }^{\circ}$ 190-191 - 1983 
TABLA 5

Sistema: cemento 3/escoria-agua de mar artificial

Portlandita: diagramas de difracción de rayos $X$.

Intensidad relativa de uno de los picos característicos

\begin{tabular}{|c|c|c|c|c|}
\hline \multirow{2}{*}{$\begin{array}{c}\text { Cemento 3/escoria } \\
\text { en peso }\end{array}$} & \multicolumn{4}{|c|}{ Edad, dias } \\
\cline { 2 - 5 } & $\mathbf{2 2 + 5 6}$ & $\mathbf{2 2 + 9 0}$ & $\mathbf{2 2 + 1 8 0}$ & $\mathbf{2 2 + 3 6 0}$ \\
\hline $100 / 0$ & $20(22)$ & $20(18)$ & $18(18)$ & $12(22)$ \\
$85 / 15$ & $12(21)$ & $2(14)$ & $10(17)$ & $16(18)$ \\
$65 / 35$ & $1(19)$ & $-(12)$ & $-(15)$ & $-(3)$ \\
$40 / 60$ & $2(6)$ & $-(4)$ & $-(6)$ & $-(+)$ \\
$30 / 70$ & $-(5)$ & $-(2)$ & $-(+)$ & $-(+)$ \\
\hline
\end{tabular}

$-=$ No detectado. $\quad+=$ Detectado.

T ABLA 6

Sistema: cemento 3/escoria-agua de mar artificial

Brucita: diagramas de difracción de rayos $X$.

Intensidad relativa de uno de los picos característicos

\begin{tabular}{|c|c|c|c|c|}
\hline \multirow{2}{*}{$\begin{array}{c}\text { Cemento 3/escoria } \\
\text { en peso }\end{array}$} & $\mathbf{5}$ & \multicolumn{3}{|c|}{ Edad, dias } \\
\cline { 2 - 5 } & $\mathbf{2 2 + 5 6}$ & $\mathbf{2 2 + 9 0}$ & $\mathbf{2 2 + 1 8 0}$ & $\mathbf{2 2 + 3 6 0}$ \\
\hline $100 / 0$ & 4 & 4 & 4 & 5 \\
$85 / 15$ & 4 & 3 & 4 & 10 \\
$65 / 35$ & 4 & 5 & 4 & 3 \\
$40 / 60$ & 4 & 5 & 3 & 2 \\
$30 / 70$ & 3 & 4 & + & 3 \\
\hline
\end{tabular}

$+=$ Detectado.

T A B LA 7

Sistema: cemento 3/escoria-agua de mar artificial

Calcita: diagramas de difracción de rayos $X$.

Intensidad relativa de uno de los picos característicos

\begin{tabular}{|c|c|c|c|c|}
\hline \multirow{2}{*}{$\begin{array}{c}\text { Cemento 3/escoria } \\
\text { en peso }\end{array}$} & \multicolumn{4}{|c|}{ Edad, dias } \\
\cline { 2 - 5 } & $\mathbf{2 2 + 5 6}$ & $\mathbf{2 2 + 9 0}$ & $\mathbf{2 2 + 1 8 0}$ & $\mathbf{2 2 + 3 6 0}$ \\
\hline $100 / 0$ & $5(3)$ & $6(3)$ & $8(3)$ & $8(6)$ \\
$85 / 15$ & $4(2)$ & $4(3)$ & $6(4)$ & $6(6)$ \\
$65 / 35$ & $4(3)$ & $6(3)$ & $4(5)$ & $6(9)$ \\
$40 / 60$ & $4(4)$ & $5(7)$ & $4(11)$ & $5(16)$ \\
$30 / 70$ & $4(3)$ & $7(5)$ & $4(12)$ & $3(11)$ \\
\hline
\end{tabular}




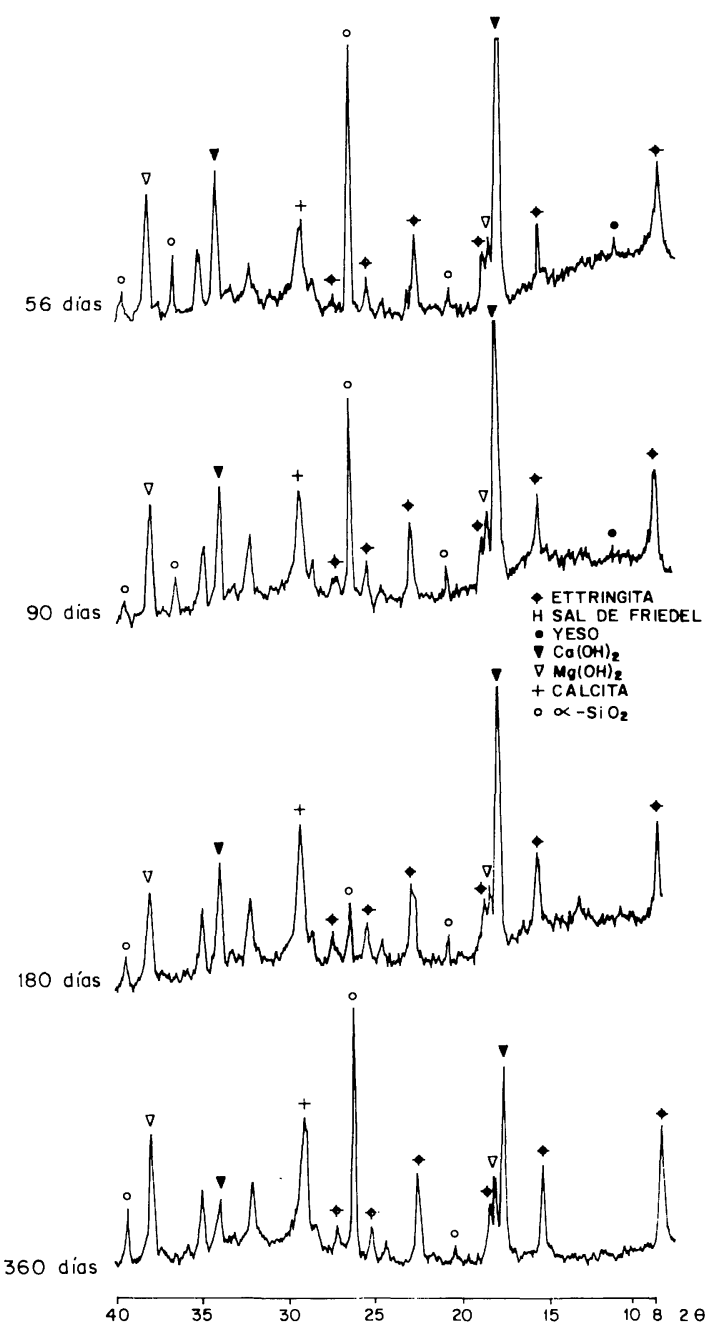

Fig. 7.-Sistema: cemento 3/escoria-agua de mar artificial. Mezcla: cemento $3 /$ escoria $=100 / 0$ (en peso). DRX de la fracción enriquecida. mayor (1,5 a 3 veces) que la de los diagramas de las fracciones extraídas de probetas análogas sumergidas en agua potable filtrada.

- Sal de Friedel: En este caso, no se han detectado los picos de la sal de Friedel.

- Yeso: Los picos del yeso, de pequeña intensidad, se han detectado en los diagramas de difracción de rayos $\mathrm{X}$ correspondientes a las muestras de las dos primeras edades $(22+56$ y $22+90$ dias $)$.

- Portlandita: La intensidad de los picos de este compuesto, máxima de todo el conjunto del sistema presente, disminuye con el tiempo de conservación-ataque.

- Brucita: Los picos de la brucita se han detectado en los DRX de las cuatro muestras extraidas de las correspondientes series de probetas de mortero sumergidas en agua de mar artificial; su intensidad es del mismo orden en los diagramas de las tres primeras edades y ligeramente superior en la cuarta.

- Calcita: La intensidad de los picos de este compuesto, que se han detectado en los cuatro DRX, experimenta un ligero incremento con el tiempo de conservación-ataque, siendo del mismo orden en las dos edades mayores.

- Mezcla: cemento $3 /$ escoria $=85 / 15$, en peso, (figura 8 )

- Ettringita: Los picos de este compuesto, identificados en todos los DRX, presentan mayor intensidad que en los diagramas de difracción de rayos $\mathrm{X}$ de las muestras análogas sumergidas en agua potable filtrada.

La intensidad de los picos en los DRX de las tres primeras edades es del mismo orden y superior en la cuarta.

- Sal de Friedel: Los picos de la sal de Friedel se han identificado en los DRX de las muestras extraidas de las cuatro series de probetas. La menor intensidad corresponde a los diagramas de las dos edades mayores.

- Yeso: En este caso, no se han detectado los picos del yeso.

- Portlandita: Los picos de la portlandita se han detectado en los cuatro diagramas de difracción de rayos $\mathrm{X}$; la mayor intensidad de dichos picos corresponde a la muestra de la serie de probetas sumergidas en agua de mar artificial durante 360 dias. La intensidad de los picos de la portlandita en el DRX de la muestra extraida de la serie de probetas de la edad $22+90$ dias es anormalmente baja. 


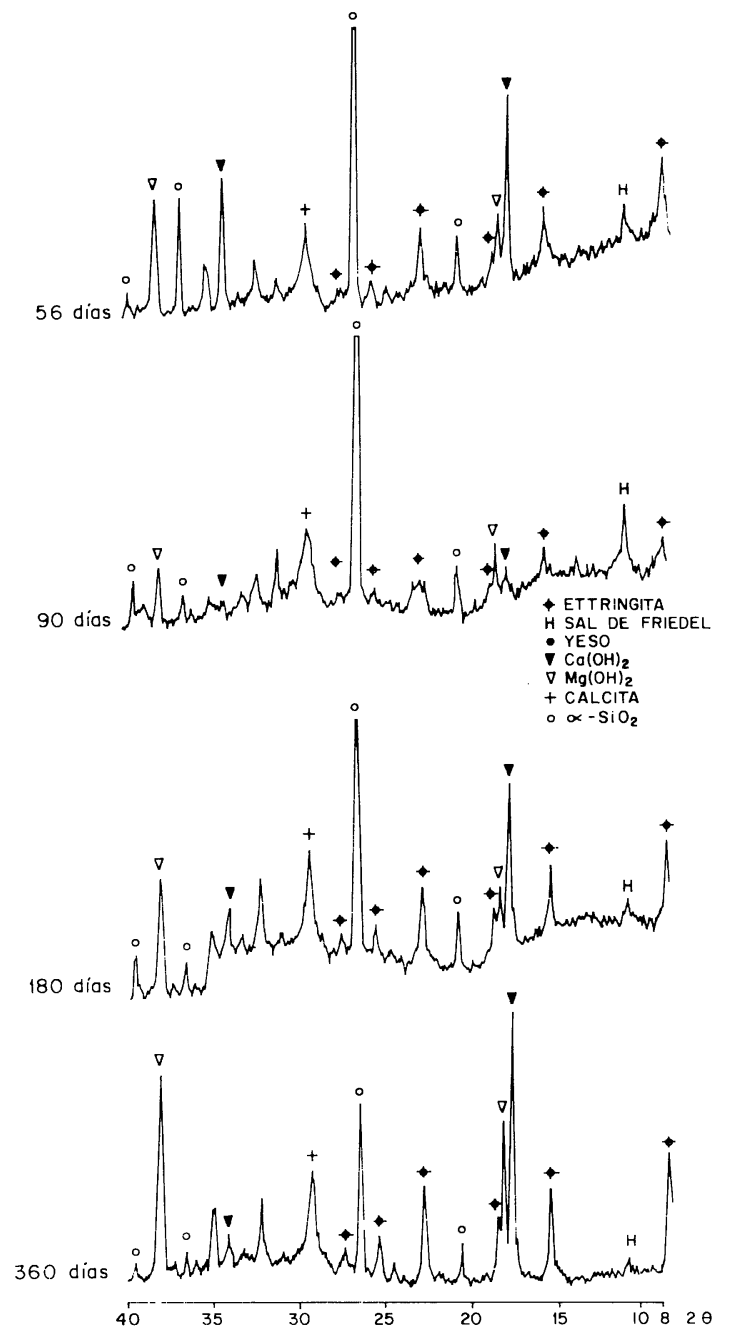

Fig. 8.-Sistema: cemento 3/escoria-agua de mar artificial. Mezcla: cemento $3 /$ escoria $=85 / 15$ (en peso). DRX de la fracción enriquecida.

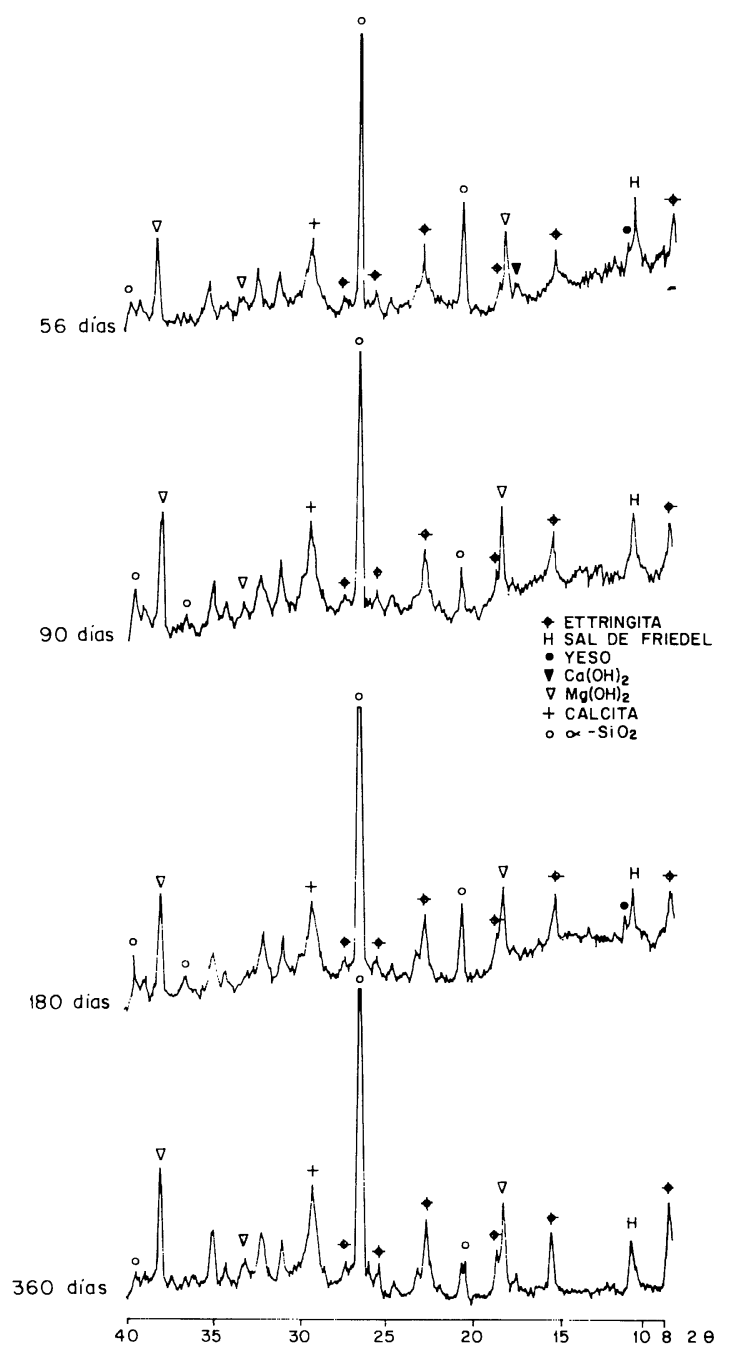

Fig. 9.-Sistema: cemento 3/escoria-agua de mar artificial. Mezcla: cemento $3 /$ escoria $=65 / 35$ (en peso). DRX de la fracción enriquecida.

- Brucita: Los picos de este compuesto se han detectado en los cuatro DRX; la mayor intensidad de dichos picos se presenta en el diagrama de la muestra que corrresponde a la edad mayor $(22+360$ diás $)$.

- Calcita: La intensidad de los picos de la calcita, identificados en todos los DRX, es análoga en los diagramas de las muestras de las dos primeras edades y ligeramente superior, y también del mismo orden, en las dos edades restantes.

- Mezcla: cemento $3 /$ escoria $=65 / 35$, en peso, (figura 9)

- Ettringita: Los picos de la ettringita, que aparecen en todos los DRX, presentan mayor intensidad que en los diagramas de difracción de rayos $\mathrm{X}$ de las muestras análogas sumergidas en agua potable filtrada. Dicha intensidad es del mismo orden en los DRX de las muestras correspondientes a las tres primeras edades y ligeramente superior en la cuarta.

- Sal de Friedel: La intensidad de los picos de este compuesto, que aparecen en los cuatro DRX, es del mismo orden en los corrrespondientes a las dos primeras edades, así como en las otras dos edades restantes (en éstas es inferior a la de las anteriores edades). 
- Yeso: Los picos del yeso, de pequeña intensidad, se han detectado en los diagramas de difracción de rayos $\mathrm{X}$ que corresponden a las muestras extraidas de las probetas sumergidas en agua de mar artificial durante 56 y 180 dias.

- Portlandita: Unicamente, se han detectado los picos de la portlandita, de pequeña intensidad, en el diagrama de difracción de rayos $\mathrm{X}$ que corresponde a la muestra extraida de las probetas sumergidas durante 56 dias en agua de mar artificial.

- Brucita: Los picos de este compuesto se han detectado en los cuatro DRX.

- Calcita: La intensidad de los picos de la calcita, detectados en los cuatro DRX, es del mismo orden en los diagramas de las muestras correspondientes a $22+56$ días y $22+180$ días, por una parte, y $22+90$ días y $22+360$ días, por otra.

- Mezcla: cemento 3/escoria $=40 / 60$, en peso, (figura 10 ).

- Ettringita: Los picos de este compuesto, que se han detectado en todos los DRX de esta mezcla, presentan análoga intensidad o superior que la de los diagramas de las series de probetas análogas del sistema cemento 3/escoria-agua potable filtrada.

- Sal de Friedel: Los picos de la sal de Friedel se han detectado en los cuatro DRX, presentando una intensidad comprendida en un entorno relativamente pequeño.

- Yeso: Unicamente, se han detectado los picos de este compuesto en el DRX de la muestra que corresponde a la serie de probetas sumergidas durante 90 días.

- Portlandita: Los picos de la portlandita, con pequeña intensidad, se han detectado, únicamente, en el diagrama de difracción de rayos $\mathrm{X}$ de la muestra extraída de la serie de probetas sumergidas durante 56 dias.

- Brucita: Los picos de la brucita se han dectectado en los cuatro DRX; la intensidad de dichos picos es ligeramente inferior en los diagramas de las muestrasa que corresponden a las series de probetas de las dos edades mayores.

- Calcita: Los picos de la calcita se han detectado en los cuatro DRX; su intensidad, con relación a la de los diagramas de las muestras de las series de probetas análogas del sistema cemento 3/escoria-agua potable filtrada, es parecida en los de la primera edad e inferior en las restantes.

- Mezcla: cemento 3/escoria $=30 / 70$, en peso, (figura 11)

- Ettringita: La intensidad de los picos de la ettringita, que aparecen en los cuatro DRX, es superior que la correspondiente a las series análogas del sistema cemento 3/escoria-agua potable filtrada.

- Sal de Friedel: Los picos de este compuesto se han detectado en los cuatro diagramas de difracción de rayos $\mathrm{X}$; su intensidad es muy parecida.

- Yeso: Unicamente, se han detectado los picos del yeso en el DRX de la muestra que corresponde a la serie de probetas sumergidas durante 90 días en agua de mar.

- Portlandita: En los DRX de las muestras de las probetas de mortero hechas con esta mezcla no se han detectado los picos de la portlandita, que aparecen en los diagramas de las series de probetas análogas sumergidas en agua potable filtrada. 


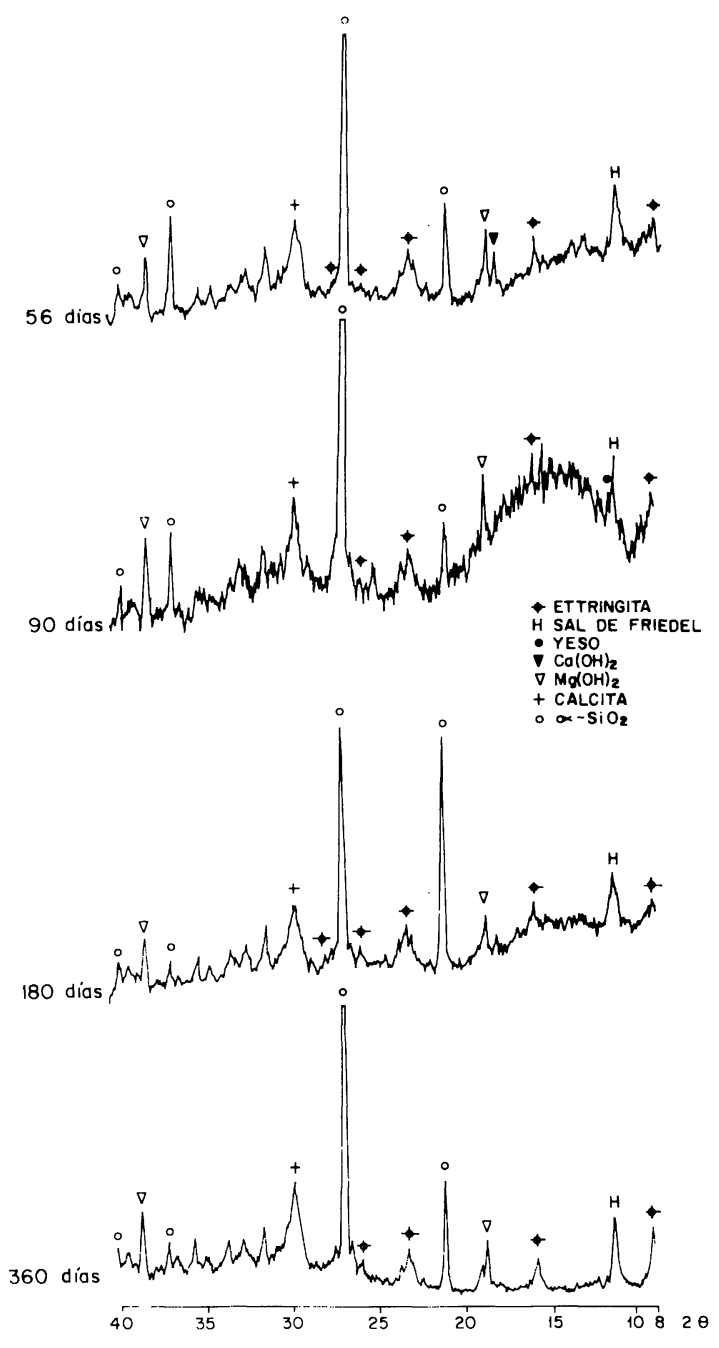

Fig. 10.-Sistema: cemento 3/escoria-agua de mar artificial.

Mezcla: cemento $3 /$ escoria $=40 / 60$ (en peso). DRX de la fracción enriquecida.

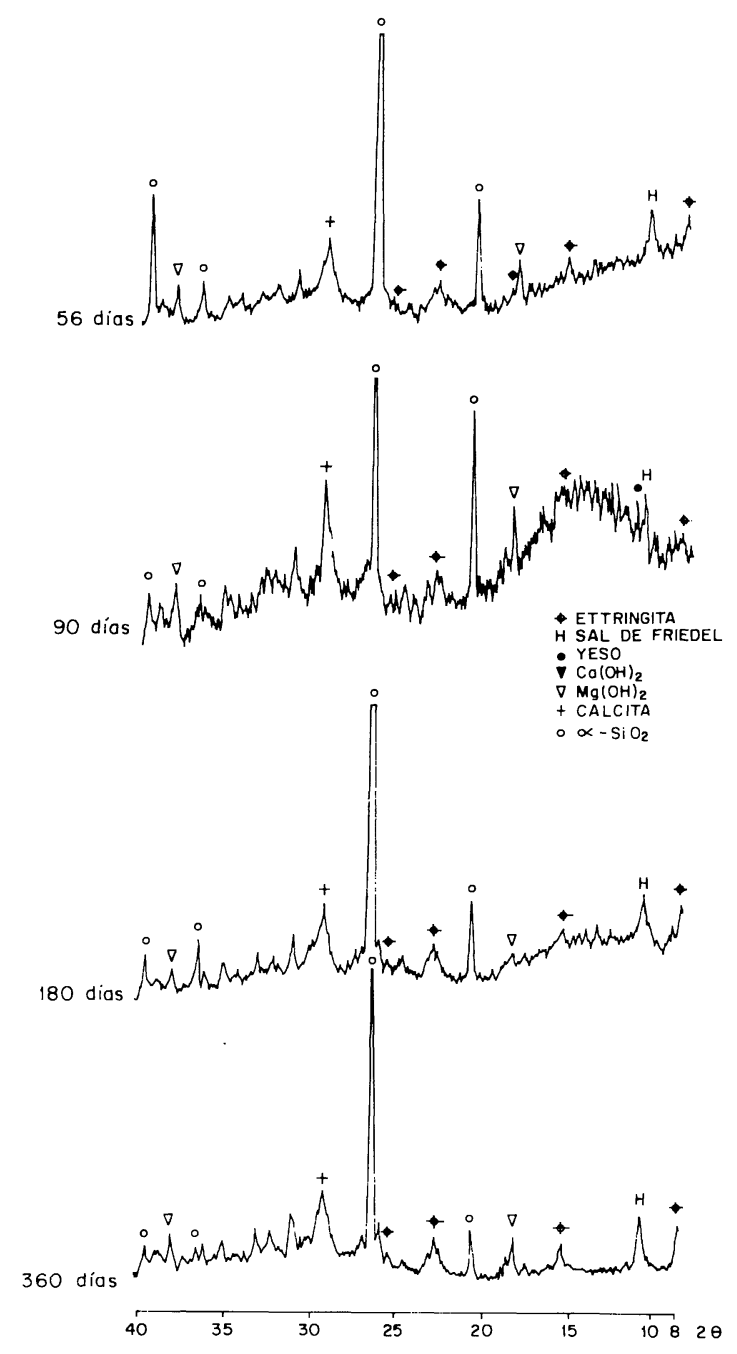

Fig. 11.-Sistema: cemento 3/escoria-agua de mar artificial.

Mezcla: cemento $3 /$ escoria $=30 / 70$ (en peso). DRX de la fracción enriquecida.

- Brucita: Los picos de la brucita se han detectado en los diagramas de difracción de rayos $\mathrm{X}$ de las muestras correspondientes a las cuatro series de probetas sumergidas en agua de mar artificial.

- Calcita: La intensidad de los picos de la calcita, que se han detectado en los cuatro DRX, es superior que la de los diagramas correspondientes a las probetas análogas sumergidas en agua potable filtrada durante las dos primeras edades e inferior en las dos edades restantes.

En resumen, para cada mezcla utilizada en la fabricación de las probetas de mortero $(1: 3)$ del sistema cemento 3/escoria-agua de mar artificial se observa, como en los casos de los sistemas de (5) (6), que la influencia de tiempo de conservación-ataque (56-90-180 y 360 días) de dichas probetas, en la formación de los diversos compuestos cristalinos identificados por DRX en la fracción enriquecida (pasta de cemento hidratado-atacado) extraida de las probetas de mortero, es mínima.

b) Influencia de la mezcla utilizada en la fabricación de las probetas de mortero, para una misma edad.

La adición de escoria al cemento 3 influye en la composición estructural de la fracción enri- 
quecida (pasta de cemento), cuando las probetas de mortero (1:3) fabricadas con las distintas mezclas cemento 3/escoria se sumergen en agua de mar artificial (ASTM), como se puede apreciar en las figuras 7 a 11 y tablas 2 a 7; este fenómeno es función, a su vez, del tiempo de conservación-ataque.

- Edad: $22+56$ dias

- Ettringita: La intensidad de los picos de este compuesto, que se han detectado en todos los DRX, disminuye con la adición de escoria. La máxima intensidad corresponde al diagrama de la muestra extraida de la probeta hecha con cemento 3 .

- Sal de Friedel: Los picos de la sal de Friedel se han identificado, sólamente, en los diagramas de difracción de rayos $\mathrm{X}$ de las muestras extraídas de las series de probetas fabricadas con las diversas mezclas de cemento 3/escoria y no con cemento 3 sin adición de escoria. La máxima intensidad de dichos picos se presenta en el DRX de ia muestra que corresponde a la mezcla cemento $3 /$ escoria $=65 / 35$, en peso.

- Yeso: Unicamente, se han detectado los picos de este compuesto en los DRX de las muestras de las probetas hechas con cemento 3 y con la mezcla cemento $3 /$ escoria $=65 / 35$, en peso.

- Portlandita: La intensidad de los picos de la portlandita en los DRX correspondientes disminuye conforme lo hace la cantidad de clínker, o lo que es lo mismo aumenta la de escoria, en la mezcla cemento 3/escoria utilizada para fabricar las distintas series de probetas de mortero; dichos picos no se han detectado en el diagrama de difracción de rayos $\mathrm{X}$ de la muestra extraida de la serie de probetas hecha con la mezcla que tiene el mayor contenido de escoria $(70 \%)$.

- Brucita: Los picos de este compuesto se han identificado en todos los DRX; su intensidad es análoga en los diagramas de las muestras que corresponden a las probetas hechas con cemento $3 /$ escoria $=100 / 0,85 / 15,65 / 35$ y 40/60 (en peso) y ligeramente inferior en la mezcla restante (cemento $3 /$ escoria $=30 / 70$, en peso).

- Calcita: Los picos de la calcita, con una intensidad parecida, se han detectado en todos los DRX.

- Edad: $22+90$ días

- Ettringita: Los picos de la ettringita se han identificado en todos los DRX; la mayor intensidad se presenta en el diagrama de la muestra extraida de la probeta hecha con cemento 3 sin adición de escoria.

- Sal de Friedel: Como en el caso anterior, los picos de la sal de Friedel se han detectado en los diagramas de difracción de rayos $\mathrm{X}$ de las muestras que corresponden a las series de probetas fabricadas con las diversas mezclas cemento 3-escoria, estudiadas en este sistema. La máxima intensidad se presenta en los DRX de las muestras de las probetas hechas con cemento $3 /$ escoria $=65 / 35$ y $40 / 60$ (en peso).

- Yeso: Los picos del yeso se han identificado en los DRX de las muestras correspondientes a las series de probetas hechas con cemento $3 /$ escoria $=100 / 0,40 / 60$ y 30/70 (en peso).

- Portlandita: Los picos de este compuesto, únicamente, se han detectado en los DRX de las muestras extraidas de las series de probetas fabricadas con cemento 3 , que presentan la máxima intensidad, y con la mezcla que tiene el menor contenido de escoria (15\%). 
- Brucita: Los picós de la brucita se han identificado en todos los DRX, presentando la máxima intensidad en los correspondientes a las muestras de las probetas hechas con cemento $3 /$ escoria $=65 / 35$ y $40 / 60$ (en peso).

- Calcita: En este caso, también se han identificado los picos de la calcita en los cinco diagramas de difracción de rayos $\mathrm{X}$.

- Edad: $22+180$ dias

- Ettringita: La intensidad de los picos de la ettringita, que se han detectado en todos los DRX, disminuye con la adición de escoria; la mayor corresponde al diagrama de la muestra extraída de la probeta fabricada con cemento 3 y la menor al de la mezcla cemento $3 /$ escoria $=40 / 60$ (en peso).

- Sal de Friedel: Los picos de este compuesto se han detectado en los DRX de las muestras extraidas de las probetas elaboradas con las distintas mezclas cemento 3/escoria estudiadas; la menor intensidad corresponde a la mezcla que tiene el menor contenido de escoria (15\%). En los tres casos restantes, dicha intensidad, es del mismo orden.

- Yeso: Unicamente, se han detectado los picos del yeso en el DRX de la muestra que corresponde a la serie de probetas fabricadas con la mezcla cemento $3 /$ escoria $=65 / 35$ (en peso).

- Portlandita: Los picos de este compuesto, sólamente, se han detectado en los diagramas de difracción de rayos $\mathrm{X}$ de las muestras extraídas de las series de probetas hechas con cemento 3 , que presentan la máxima intensidad, y con la mezcla cemento $3 /$ escoria $=85 / 15$ (en peso).

- Brucita: Los picos de la brucita se han identificado en todos los DRX, del mismo modo que en los casos anteriores; su intensidad es del mismo orden en los diagramas de las muestras correspondientes a las series de probetas hechas con las mezclas cemento $3 /$ escoria $=100 / 0$, $85 / 15$ y $65 / 35$ (en peso), disminuyendo en los dos casos restantes.

- Calcita: Los picos de este compuesto se han detectado, como en los casos anteriores, en todos los DRX; la mayor intensidad corresponde al diagrama de la muestra extraida de la serie de probetas fabricadas con cemento 3 , sin adición de escoria.

- Edad: $22+360$ días

- Ettringita: La intensidad de los picos de este compuesto, que se han identificado en todos los DRX, disminuye con la adición de escoria, presentando en el diagrama de la muestra extraída de la serie de probetas fabricadas con cemento 3 el valor máximo y en los de las muestras que corresponden a las mezclas cemento $3 /$ escoria $=40 / 60$ y 30/70 (en peso), los valores mínimos.

- Sal de Friedel: Los picos de la sal de Friedel se han detectado en los DRX de las muestras extraídas de las series de probetas hechas con las distintas mezclas cemento 3/escoria estudiadas; la máxima intensidad de dichos picos se encuentra en el diagrama de la muestra de la serie de probetas elaborada con la mezcla que tiene el $60 \%$ de escoria y el mínimo (indicios) en el de la mezcla cemento $3 /$ escoria $=85 / 15$ (en peso).

- Yeso: En este caso, no se han detectado los picos del yeso en los diversos DRX.

- Portlandita: Los picos de la portlandita, únicamente, se han identificado en los DRX de las 
muestras que corresponden a las series de probetas fabricadas con las mezclas cemento $3 /$ escoria $=100 / 0$ y $85 / 15$ (en peso).

- Brucita: Los picos de este compuesto se han detectado en todos los DRX, presentando la máxima intensidad que se considera anormal, en el diagrama de la muestra de la mezcla cemento $3 /$ escoria $=85 / 15$ (en peso).

- Calcita: Los picos de la calcita se han identificado en todos los diagramas de difracción de rayos $\mathrm{X}$, presentando la mayor intensidad, como en los casos anteriores, en el DRX de la muestra extraida de la serie de probetas fabricadas con cemento 3 , sin adición de escoria.

En resumen, la adición de escoria al cemento 3 influye en la formación o eliminación de determinados compuestos cuando las probetas de mortero, fabricadas con dicho cemento 3 ó con las cuatro mezclas estudiadas a base de cemento 3 y de escoria, se someten durante diversos periodos de tiempo (hasta 1 año, por el momento) a la acción del agua de mar artificial ASTM D 1141-75; estos fenómenos se han puesto de manifiesto por DRX.

Asi, en los compuestos cristalinos identificados se observa lo siguiente:

a) La mayor intensidad de los picos de la ettringita, para cada edad, corresponde a los DRX de las muestras extraidas de las probetas de mortero hechas con cemento 3 y la menor intensidad a los diagramas de las mezclas que tienen los mayores contenidos de escoria $(60$ y $70 \%)$.

b) La adición de escoria en cantidades superiores al $15 \%$ favorece la formación de la sal de Friedel.

c) En determinados casos, la adición de escoria también favorece la formación de yeso secundario.

d) La intensidad de los picos de la portlandita disminuye, en los DRX correspondientes, con la adición de escoria; dichos picos llegan a desaparecer en los DRX de las muestras extraidas de las series de probetas fabricadas con las mezclas cemento $3 /$ escoria $=65 / 35$ y $40 / 60$ (en peso) para las tres edades mayores y $30 / 70$ (en peso) para todas las edades.

e) La minima intensidad de los picos de la brucita corresponde, por regla general, a los diagramas de difracción de rayos $\mathrm{X}$ de las muestras de las probetas hechas con las mezclas que tienen el mayor contenido de escoria ( $70 \%)$.

f) En la mayoria de los casos estudiados, la intensidad máxima de los picos de la calcita corresponde a los DRX de las muestras de las distintas series de probetas hechas con cemento 3 , sin adición de escoria.

Por otra parte, si se comparan los sistemas cemento 3/escoria-agua potable filtrada y cemento 3/escoria-agua de mar artificial (ASTM D1141-75), en donde diversas series análogas de probetas de mortero se han sometido a la acción de dichos medios durante distintos periodos de tiempo, se observa que cuando dichas probetas se sumergen en agua de mar artificial se favorece la formación de ettringita, la de yeso (en determinados casos) y la de calcita cuando las probetas de mortero se han fabricado con cemento 3 y con la mezcla cemento $3 /$ escoria $=85 / 15$ (en peso); por el contrario, la formación de portlandita, así como la de calcita, en los casos restantes, se ve disminuida. 


\section{INTERPRETACION DE RESULTADOS}

En el sistema' cemento 3/escoria-agua de mar artificial (ASTM D1141-75), objeto de la presente publicación, se producen un conjunto de procesos fisicoquimicos que dan lugar a la variación de la composición iónica del agua de mar artificial $(*)$ en donde han estado sumergidas las probetas de mortero, a la formación de una fase sólida en el seno de dicha agua de mar y a la formación de nuevos compuestos en la pasta de cemento, así como al incremento o disminución de otros existentes en dicha pasta de cemento; fenómenos que se han puesto de manifiesto en los sistemas cemento 1/escoria-agua de mar artificial (ASTM D1141-75) y cemento 2/escoria-agua de mar artificial (ASTM D1141-75) estudiados, de los que se dio cuenta en (5) (6).

El Ca (II) presente en el agua de mar artificial $\left(1,30 \times 10^{2}\right.$ moles/litro) experimenta, en la mayoria de los casos de este sistema, un incremento debido, fundamentalmente, a la disolución de parte del $\mathrm{Ca}(\mathrm{OH})_{2}$ formado durante las reacciones de hidratación del cemento, según el equilibrio:

$$
\mathrm{Ca}(\mathrm{OH})_{2} \text {. sólido } \stackrel{\mathrm{H}_{2} \mathrm{O} \text { mar }}{\rightleftarrows} \mathrm{Ca}(\mathrm{OH})_{2} \text {.disuelto } \stackrel{\mathrm{H}_{2} \mathrm{O} \text { mar }}{\rightleftarrows} \mathrm{Ca}(\mathrm{II})+2 \mathrm{OH}(\mathrm{I})
$$

produciendo un aumento de la basicidad del medio y, por consiguiente, del valor del $\mathrm{pH}$.

El valor del $\mathrm{pH}$ del agua de mar artificial (6.5) alcanza valores superiores a 11.0 en los medios en donde han estado sumergidas las probetas de mortero hechas con cemento 3 y con la mezcla de dicho cemento y el $15 \%$ de escoria: en los restantes medios de conservación-ataque se encuentra comprendido entre 7.5 y 10 para la serie de probetas fabricadas con la mezcla cemento $3 /$ escoria $=65 / 35$ (en peso) $\div 7.5$ a 8.5 para las mezclas $40 / 60$ y $30 / 70$ (en peso). debido a la menor cantidad de $\mathrm{Ca}(\mathrm{OH})_{2}$ puesta en juego, ya que existe menor cantidad de clinker y que parte de dicho hidroxido ha reaccionado con la escoria para dar los correspondientes compuestos de calcio.

El contenido de Ca (II) presente en el agua de mar artificial $\left(1,30 \times 10^{2}\right.$ moles/litro $)$ ha pasado a ser superior a $3 \times 10^{2} \mathrm{moles} /$ litro en los tres primeros casos, que corresponden a las mezclas cemento $3 /$ escoria $=100 / 0,85 / 15$ y $65 / 35$ (en peso), y ligeramente superior, o del mismo orden, en los dos casos restantes (mezclas cemento $3 /$ escoria $=40 / 60$ y $30 / 70$, en peso).

El $\mathrm{Mg}$ (II) del agua de mar artificial $\left(5.54 \times 10^{2}\right.$ moles/litro $)$ ha desaparecido total o parcialmente en los distintos casos estudiados, precipitando como $\mathrm{Mg}(\mathrm{OH})_{2}$ en el agua dando lugar. en este caso. a una nueva fase sólida.

El $\mathrm{Mg}$ (II) precipita como $\mathrm{Mg}(\mathrm{OH})_{2}$ en medio básico fuerte por cumplirse:

$$
|\mathrm{Mg}(\mathrm{II})||\mathrm{OH}(\mathrm{I})|^{2}>\text { Ps }\left(1.8 \times 10^{11}\right)
$$

produciéndose la reacción:

$$
\mathrm{Mg}(\mathrm{II})+2 \mathrm{OH}(\mathrm{I}) \rightleftharpoons \mathrm{Mg}(\mathrm{OH})_{2} \text {. sólido }
$$

y disminuyendo el valor del $\mathrm{pH}$.

El $\mathrm{Mg}$ (II) de una disolución $10^{2} \mathrm{M}$ precisa un $\mathrm{pH}=10.6$ para que precipite como $\mathrm{Mg}(\mathrm{OH})_{2}$ (7), dando lugar a la reacción (B). Así. en este trabajo se ha probado, como en (5) (6). que el $\mathrm{Mg}$ (II) ha precipitado como tal hidróxido de magnesio (brucita). dando lugar a la nueva fase

(*) De la variación de la composicion ionica del agua de mar artificial se dará cuenta en una proxima publicacion 
sólida, en aquellos medios (agua de mar artificial) en donde han estado sumergidas las probetas de mortero hechas con cemento 3 y con la mezcla que tiene el $15 \%$ de escoria, en los que el $\mathrm{pH}$ es superior a 11,5; por el contrario, en los medios de los restantes casos no ha precipitado por no darse las condiciones adecuadas. El Mg (II) del agua de mar artificial ha desaparecido por haber precipitado en el medio (nueva fase sólida) y en el seno de las probetas en los dos primeros casos, mientras que en los restantes se encuentra parcialmente, habiendo precipitado el resto en las probetas de mortero.

Por otra parte, el $\mathrm{CO}_{2}$ disuelto en el agua de mar es capaz de reaccionar con el $\mathrm{Ca}$ (II), en medio básico fuerte, para formar $\mathrm{CaCO}_{3}$.sólido, según:

$$
\mathrm{CO}_{2}+\mathrm{Ca}(\mathrm{II})+2 \mathrm{OH}(\mathrm{I}) \stackrel{\mathrm{H}_{2} \mathrm{O} \text { mar }}{\rightleftarrows} \mathrm{CaCO}_{3} \text {.sólido }+\mathrm{H}_{2} \mathrm{O}
$$

siempre que se cumpla:

$$
[\mathrm{Ca}(\mathrm{II})]\left[\mathrm{CO}_{3}(\mathrm{II})\right]>\mathrm{P}^{\prime}{ }_{\mathrm{s}}\left(4,8 \times 10^{-9}\right)
$$

a la vez, se produce una disminución de la concentración de iones $\mathrm{OH}(\mathrm{I})$, descendiendo, por consiguiente, el valor del $\mathrm{pH}$.

La disminución de los iones $\mathrm{OH}$ (I), equilibrios (B) y (C), y del Ca (II), equilibrio (C), del agua de mar artificial favorecé la reacción (A), es decir la disolución del $\mathrm{Ca}(\mathrm{OH})_{2}$ y, por consiguiente, el avance de las reacciones de hidratación de los compuestos del clinker, por lo que se libera más portlandita que pasa, en parte, al medio en forma iónica, a la vez que se degradan los correspondiente silicatos.

El precipitado de carbonato de calcio, que se encuentra en la nueva fase sólida, aparece como calcita y como aragonito en proporciones distintas, predominando uno sobre otro según las condiciones del sistema y, de un modo especial, de la mezcla utilizada en la fabricación de las probetas de mortero, que influye en las caracteristicas del agua de mar artificial en donde han estado sumergidas durante distintos periodos de tiempo $(\mathrm{pH}$, concentración de los iones presentes y formación de una nueva fase sólida), como se señaló en otras publicaciones (5) (6) (8) (9).

En este trabajo, también se ha probado que la calcita predomina sobre el aragonito en aquellos casos cuyas condiciones finales del medio (agua de mar artificial), en donde han estado sumergidas las probetas de mortero, son las siguientes:

a) $\mathrm{El} \mathrm{pH}$ es mayor de 11; el original es 6,5,

b) La concentración de Ca (II) es superior a 3,5 $\times 10^{-2}$ moles/litro; la inicial es $1,30 \times 10^{-2}$ moles/litro,

c) El contenido de $\mathrm{Mg}$ (II) es nulo o menor de $0,5 \times 10^{-2} \mathrm{moles} / \mathrm{litro}$,

d) Se ha formado una fase sólida en la que se han detectado los compuestos cristalinos aragonito, en pequeña cantidad, calcita y brucita,

como sucede en el agua de mar artificial en donde han estado sumergidas las diversas series de probetas hechas con cemento 3 y con la mezcla cemento $3 /$ escoria $=85 / 15$ (en peso).

El aragonito predomina sobre la calcita en aquellos casos cuyas condiciones del medio, en donde han estado sumergidas las probetas de mortero, son las siguientes: 
a) $\mathrm{El} \mathrm{pH}$ se encuentra comprendido entre 7,5 y 8,5 ,

b) La concentración de $\mathrm{Ca}$ (II) es superior a $1,30 \times 10^{-2}$ moles/litro e inferior a $2 \times 10^{-2}$ moles/litro,

c) El contenido de $\mathrm{Mg}$ (II) es superior a $2,5 \times 10^{-2}$ moles/litro e inferior a 3,5 $\times 10^{-2}$ moles/litro,

d) Existe una fase sólida en donde se han detectado los compuestos cristalinos calcita, en pequeña cantidad, y aragonito,

como sucede en el agua de mar artificial en donde han estado sumergidas las distintas series de probetas de mortero fabricadas con las mezclas cemento $3 /$ escoria $=40 / 60$ y $30 / 70$ (en peso).

En los medios en donde han estado sumergidas las series de probetas elaboradas con cemento $3 /$ escoria $=65 / 35$ (en peso) las cantidades de calcita y aragonito son del mismo orden o predomina una forma sobre otra, sin llegar a alcanzar las magnitudes de los casos anteriores. En este sistema parcial la cantidad de Ca (II) se encuentra comprendida entre $2,8 \times 10^{-2}$ moles/litro y $3,5 \times 10^{-2} \mathrm{moles} / \mathrm{litro}$, la de $\mathrm{Mg}$ (II) es menor de $1 \times 10^{-2} \mathrm{moles} /$ litro y el $\mathrm{pH}$ se encuentra en el entorno 7,3 a 10; en la fase sólida formada se han detectado los compuestos cristalinos calcita y aragonito.

En resumen, la presencia de $\mathrm{Mg}$ (II) en la disolución (agua de mar artificial) que, a su vez, depende de la concentración de iones $\mathrm{OH}(\mathrm{I})$, tiene una influencia extraordinaria en la formación del aragonito, así como las cantidades relativas de Ca (II) y de $\mathrm{Mg}$ (II), como se ha puesto de manifiesto en otros trabajos (5) (6) (8) (9). La cantidad de Ca (II) es la suma del Ca (II) del agua de mar artificial y la procedente del $\mathrm{Ca}(\mathrm{OH})_{2}$ del cemento hidratado que se ha disuelto y no ha precipitado, mientras que la de $\mathrm{Mg}$ (II) corresponde a la que queda en dicha agua de mar artificial por haberse eliminado, total o parcialmente, al precipitar como $\mathrm{Mg}(\mathrm{OH})_{2}$ en las probetas de mortero o, en determinados casos, en el medio.

La cantidad de fase sólida formada en el sistema cemento 3/escoria-agua de mar artificial, carbonato de calcio e hidróxido de magnesio que han precipitado, es función de la mezcla utilizada en la fabricación de las diversas series de probetas de mortero y del tiempo que han estado sumergidas en el agua de mar artificial. En este trabajo se ha probado que dicha fase sólida aumenta, para cada mezcla con la edad de conservación-ataque y para cada edad conforme es menor la cantidad de escoria de la mezcla, debido, fundamentalmente, al $\mathrm{Ca}(\mathrm{OH})_{2}$ puesto en juego que no ha reaccionado con los compuestos de la escoria y que se ha disuelto en el agua de mar artificial, dando lugar a las reacciones de carbonatación y a las de formación del $\mathrm{Mg}(\mathrm{OH})_{2}$, cuando se dan las condiciones favorables, reseñadas anteriormente.

En las fracciones enriquecidas (pasta de cemento) extraidas de las distintas series de probetas de mortero, sumergidas durante $56-90-180$ y 360 dias en agua de mar artificial, se han formado unos compuestos que no existían, brucita y sal de Friedel, han desaparecido otros, portlandita en ciertos casos, y el resto ha experimentado modificaciones dignas de consideración. Por DRX se han identificado los siguientes compuestos cristalinos:

- Ettringita, $3 \mathrm{CaO} . \mathrm{Al}_{2} \mathrm{O}_{3} .3 \mathrm{CaSO}_{4} .31 \mathrm{H}_{2} \mathrm{O}$; la intensidad de los picos de este compuesto, que se ha dectectado en todos los DRX, es mayor que en los diagramas de difracción de rayos $\mathrm{X}$ correspondientes a las muestras extraidas de las probetas de mortero de las series análogas sumergidas en agua potable filtrada durante los mismos periodos de tiempo. Este incremento se debe a la mayor cantidad de ettringita presente que se ha formado, de un modo especial, por reacción de los iones $\mathrm{SO}_{4}$ (II) del agua de mar artificial con los iones $\mathrm{Ca}$ (II) del $\mathrm{Ca}(\mathrm{OH})_{2}$ presente en la interfase de las probetas de mortero (reacción $\mathrm{D}$ ), que produce yeso 
secundario, y con el aluminato de calcio hidratado del cemento, según la reacción E:

$$
\mathrm{Ca}(\mathrm{OH})_{2} \text {. sólido } \rightleftarrows \mathrm{Ca}(\mathrm{OH})_{2} \text {.disuelto } \rightleftarrows \underbrace{\mathrm{Ca}(\mathrm{II})+2 \mathrm{OH}(\mathrm{I})}_{+}
$$

(E) $3 \mathrm{CaSO}_{4} \cdot 2 \mathrm{H}_{2} \mathrm{O}+3 \mathrm{CaO} \cdot \mathrm{Al}_{2} \mathrm{O}_{3} \cdot 12 \mathrm{H}_{2} \mathrm{O}+19 \mathrm{H}_{2} \mathrm{O} \rightleftarrows 3 \mathrm{CaO}_{2} \mathrm{Al}_{2} \mathrm{O}_{3} \cdot 3 \mathrm{CaSO}_{4} \cdot 31 \mathrm{H}_{2} \mathrm{O}$

y porque, además, la escoria presente en el cemento puede dar lugar a la formación de ettringita (5) (6) por reacción de los aluminatos de la misma con el $\mathrm{Ca}(\mathrm{OH})_{2}$ de la fracción hidratada del clínker, en la interfase $\mathrm{Ca}(\mathrm{OH})_{2}$. sólido $\rightleftarrows \mathrm{Ca}(\mathrm{OH})_{2}$. disuelto, y con el $\mathrm{CaSO}_{4} \cdot 2 \mathrm{H}_{2} \mathrm{O}$ secundario formado como se ha señalado anteriormente (reacción $\mathrm{D}$ ), de acuerdo con la siguiente reacción:

(F) $2 \mathrm{CaO} \cdot \mathrm{Al}_{2} \mathrm{O}_{3}+\mathrm{Ca}(\mathrm{OH})_{2}+3 \mathrm{CaSO}_{4} \cdot 2 \mathrm{H}_{2} \mathrm{O}+30 \mathrm{H}_{2} \mathrm{O} \rightleftarrows 3 \mathrm{CaO} \cdot \mathrm{Al}_{2} \mathrm{O}_{3} \cdot 3 \mathrm{CaSO}_{4} \cdot 31 \mathrm{H}_{2} \mathrm{O}$ (escoria vitrea)

lo que hace que en este sistema la mezcla cemento 3/escoria utilizada para fabricar las diversas series de probetas pueda influir en la cantidad de ettringita total formada (ettringita originada por el clínker + ettringita originada por la escoria) presentando, a veces, valores de magnitud parecida a cuando se utiliza cemento 3 sin adición de escoria.

Asi mismo, la cantidad de ettringita formada en este sistema es mayor que la de los dos sistemas estudiados en (5) (6), correspondientes al cemento $1<>$ P-550-ARI y al cemento $2<>$ P-450-Y, dada su composición estructural $\mathrm{y}$, de un modo especial, el mayor contenido de $\mathrm{C}_{3} \mathrm{~A}$ y $\mathrm{C}_{4} \mathrm{AF}$.

- Sal de Friedel, $3 \mathrm{CaO} \cdot \mathrm{Al}_{2} \mathrm{O}_{3} \cdot \mathrm{CaCl}_{2} \cdot 10 \mathrm{H}_{2} \mathrm{O}$; los picos de este compuesto se han detectado en los diagramas de difracción de rayos $\mathrm{X}$ de las muestras correspondientes a las probetas hechas con las diversas mezclas cemento 3/escoria, sumergidas en agua de mar artificial durante las tres primeras edades. La sal de Friedel se ha formado por reacción, en medio básico, de los iones $\mathrm{Cl}$ (I) de dicha agua de mar artificial con los iones Ca (II) procedentes del $\mathrm{Ca}(\mathrm{OH})_{2}$, en la interfase $\mathrm{Ca}(\mathrm{OH})_{2}$. sólido $\rightleftarrows \mathrm{Ca}(\mathrm{OH})_{2}$.disuelto, y con los aluminatos de calcio hidratados según:

$$
\begin{aligned}
& 2 \mathrm{Cl}(\mathrm{I})+\mathrm{Ca}(\mathrm{II})+3 \mathrm{CaO} \cdot \mathrm{Al}_{2} \mathrm{O}_{3} \cdot 6 \mathrm{H}_{2} \mathrm{O}+4 \mathrm{H}_{2} \mathrm{O} \rightleftarrows 3 \mathrm{CaO} \cdot \mathrm{Al}_{2} \mathrm{O}_{3} \cdot \mathrm{CaCl}_{2} \cdot 10 \mathrm{H}_{2} \mathrm{O} \\
& \mathrm{CaCl}_{2}
\end{aligned}
$$

Los iones $\mathrm{Cl}$ (I) penetran en las probetas de mortero por su gran movilidad, mayor que la de los iones sulfato (10) (11) (12), facilitando la formación de la sal de Friedel; la difusión de los iones cloruros no solo depende de la compacidad de las probetas de mortero, de la cantidad de escoria en la mezcla utilizada para elaborar las series de probetas, de la relación agua/cemento, como se ha visto en otros trabajos (5) (6) (8), sino de la capacidad de intercambio de los sistemas (13), que es función de las caracteristicas estructurales de la fracción clinker de los cementos y de la escoria; todo ello influye en las caracteristicas del agua de mar artificial en donde han estado sumergidas las probetas de mortero.

En este trabajo, se ha probado que la presencia de escoria en la mezcla empleada para fabricar las probetas de mortero, asi como su cantidad y caracteristicas, influye de un modo especial en la formación de la sal de Friedel. 
- Yeso, $\mathrm{CaSO}_{4} \cdot 2 \mathrm{H}_{2} \mathrm{O}$; se ha detectado en cantidades análogas o ligeramente superiores a las del sistema cemento 3/escoria-agua potable filtrada, en 6 casos. Este compuesto puede proceder de la reacción de los iones $\mathrm{SO}_{4}$ (II) del agua de mar artificial con el $\mathrm{Ca}$ (II) del $\mathrm{Ca}(\mathrm{OH})_{2}$ de la pasta de cemento, dando lugar al yeso secundario; reacción que se ve favorecida por la formación de brucita y de calcita, disminuyendo el valor del $\mathrm{pH}$ y por consiguiente la concentración de iones $\mathrm{OH}(\mathrm{I})$.

- Portlandita, $\mathrm{Ca}(\mathrm{OH})_{2}$; que procede de las reacciones de hidratación de los compuestos del clínker $\left(\mathrm{C}_{3} \mathrm{~S}, \mathrm{C}_{2} \mathrm{~S}\right.$ y $\mathrm{CaO}$ libre); únicamente, se ha detectado en los DRX de determinadas muestras, de un modo especial, de las probetas hechas con cemento 3 y con la mezcla que tiene el $15 \%$ de escoria, en peso. En otros casos no se ha puesto de manifiesto porque ha reaccionado en estado naciente, una parte, con la escoria para dar los correspondientes compuestos cálcicos y con el $\mathrm{CO}_{2}$ disuelto en el agua de mar, por otra parte, para formar calcita en la probeta; el resto se ha disuelto en dicha agua de mar.

- Brucita, $\mathrm{Mg}(\mathrm{OH})_{2}$; que se ha formado por reacción del $\mathrm{Mg}$ (II) del agua de mar artificial con los iones $\mathrm{OH}$ (I) procedentes del $\mathrm{Ca}(\mathrm{OH})_{2}$, generado en las reaciones de hidratación, según:

$$
\mathrm{Ca}(\mathrm{OH})_{2} \text {. sólido } \rightleftarrows \mathrm{Ca}(\mathrm{OH})_{2} \text {.disuelto } \rightleftarrows \underbrace{\mathrm{Ca}(\mathrm{II})+2 \mathrm{OH}(\mathrm{I})}_{\begin{array}{c}
+ \\
\mathrm{Mg}(\mathrm{II})
\end{array}}
$$

Para que esta reacción tenga lugar en el seno de las probetas de mortero se necesita que dichos iones $\mathrm{Mg}$ (II) penetren en ellas, se pongan en contacto con los iones $\mathrm{OH}$ (I) mencionados anteriormente y se cumpla la siguiente condición:

$$
[\mathrm{Mg}(\mathrm{II})][\mathrm{OH}(\mathrm{I})]^{2}>\mathrm{Ps}\left(1,8 \times 10^{-11}\right)
$$

El grado de difusión y la movilidad de los iones $\mathrm{Mg}$ (II) en las probetas de mortero depende de su compacidad y de la mezcla utilizada para su fabricación.

- Calcita, $\mathrm{CaCO}_{3}$; este compuesto se ha formado por reacción, en medio básico fuerte, del $\mathrm{CO}_{2}$ disuelto en el agua de mar artificial con el $\mathrm{Ca}$ (II) del $\mathrm{Ca}(\mathrm{OH})_{2}$ de la pasta de cemento, según:

$$
\mathrm{Ca}(\mathrm{OH})_{2} \text {. sólido } \rightleftarrows \mathrm{Ca}(\mathrm{OH})_{2} \text {.disuelto } \rightleftarrows \underbrace{\mathrm{Ca}(\mathrm{II})+2 \mathrm{OH}(\mathrm{I})}_{+}
$$

por cumplirse:

$$
[\mathrm{Ca}(\mathrm{II})]\left[\mathrm{CO}_{3}(\mathrm{II})\right]>\text { P's }\left(4,8 \times 10^{-9}\right)
$$

produciendo, a la vez, una disminución del $\mathrm{pH}$. En esta reacción también influye, como en los casos anteriores, el grado de difusión del $\mathrm{CO}_{2}$ en las probetas de mortero. 


\section{CONCLUSIONES}

\section{Primera:}

En el sistema cemento 3/escoria-agua de mar artificial aparece una nueva fase sólida que está formada por los compuestos cristalinos calcita, en todos los casos estudiados, aragonito, en todos excepto en uno, y brucita en los medios en donde han estado sumergidas las series de probetas hechas con cemento 3 y con la mezcla de dicho cemento 3 y el $15 \%$ de escoria.

\section{Segunda:}

La composición estructural de la nueva fase sólida depende de la mezcla (cemento 3/escoria) empleada en la fabricación de las probetas de mortero, que influye en las caracteristicas del agua de mar artificial, en donde han estado sumergidas durante los diversos periodos de tiempo estudiados $[\mathrm{pH}$; concentración de los iones $\mathrm{Ca}$ (II) y $\mathrm{Mg}$ (II), fundamentalmente; cantidad de fase sólida; etc.], favoreciendo la formación de unos u otros compuestos.

\section{Tercera:}

La adición de escoria al cemento 3 influye en la composición estructural de la fracción enriquecida (cemento hidratado-atacado) extraida de las probetas de mortero, fabricadas con las diversas mezclas cemento 3/escoria estudiadas, sometidas a la acción del agua de mar artificial durante distintos periodos de tiempo.

\section{Cuarta:}

En los diagramas de difracción de rayos $\mathrm{X}$ de las diversas fracciones enriquecidas extraídas de las probetas de mortero, sumergidas en agua de mar artificial, se han identificado los picos de los siguientes compuestos cristalinos: ettringita, brucita y calcita, en todos los DRX; sal de Friedel, yeso y portlandita, en parte de ellos.

\section{Quinta:}

La intensidad de los picos de la ettringita en los DRX de las muestras que corresponden al sistema cemento 3/escoria-agua de mar artificial es superior a la de los diagramas de las muestras de las series de probetas análogas sumergidas en agua potable filtrada. Asi mismo. la intensidad de los picos de la calcita, en determinadas mezclas (de un modo especial cemento 3 . solo, y con la adición del $15 \%$ de escoria) y en determinadas edades, también es mayor.

\section{Sexta}

La intensidad de los picos de la portlandita disminuye con la adición de escoria al cemento 3 : esta disminución es función de la cantidad de dicha escoria en la mezcla utilizada para fabricar las probetas. llegando a desaparecer en los DRX de las muestras que corresponden a las series de probetas hechas con las mezclas cemento $3 /$ escoria $=65 / 35.40 / 60$ y $30 / 70$ (en peso). 


\section{BIBLIOGRAFIA}

(1) SAGRERA-MORENO. J. L. Y GASPAR-TEBAR. D.: Materiales de Construcción. 180, 99-120, (1980)

(2) GASPAR-TEBAR. D. y SAgRERA-MORENO. J. L.: Materiales de Construccion. 183, 33-44. (1981).

(3) GASPAR-TEBAR. D. y SAgRERA-MORENO. J. L.: Materiales de Construcción. 186, 40. (1982).

(4) GASPAR-TEBAR, D. y SAGRERA-MORENO, J. L.: Materiales de Construccion, 174, 48. (1979).

(5) GASPAR-TebAR. D. y SAgRERA-MORENO. J. L.: Materiales de Construccion. 186, 39-60. (1982).

(6) GASPAR-TEBAR. D. y SAGRERA-MORENO. J. L.: Materiales de Construcción. 188, 37-58, (1982).

(7) CHARlOT, G.: L’Anal. Qual. et les Réactions en Solution; Masson et Cic: Paris (1963), págs. 213-214.

(8) GASPAR-TEBAR. D. y SAGRERA-MORENO. J. L.: Materiales de Construcción. 176, 49-77. (1979).

(9) GARCIA-AlvareZ. M. ${ }^{a}$ P.: Tesina fin de carrera. Fac. Ciencias Quimicas (Univ. Complutense. Madrid): hecha bajo la dirección de GASPAR-TEBAR, D.: Madrid. (1979).

(10) REgourd, M.: HORNAIN. H. et MORTUREUX, B.: Rev. des Mat. de Const.. 687. 72. (1974).

(11) Regourd, M.: Ann. de L'Inst. Tech. du Bât. et des Tra. Publ.: 329, 95. (1975).

(12) ONO. M.: NAGASHIMA. M.: OTSUKA. K. and ITO. T.: Rev. of the Thirty-second Gen.Meeting: Technical Session-Held in Tokyo. (1978), págs. 59-60.

(13) GJÖRV. O. E. and VENNESLAND, Ö: Cem. and Conc. Res.. 2, 229-238. (1979).

\section{RECONOCIMIENTO}

Nuestro más sincero agradecimiento a las personas del Equipo de Durabilidad del IETcc: Amalia Rodríguez Pereira, Lucila López Solana, Felipe Cantero Palacios y Manuel Cantero Palacios por su valiosa colaboración en la realización de este trabajo.

\section{publicación del IET.T.c.c.}

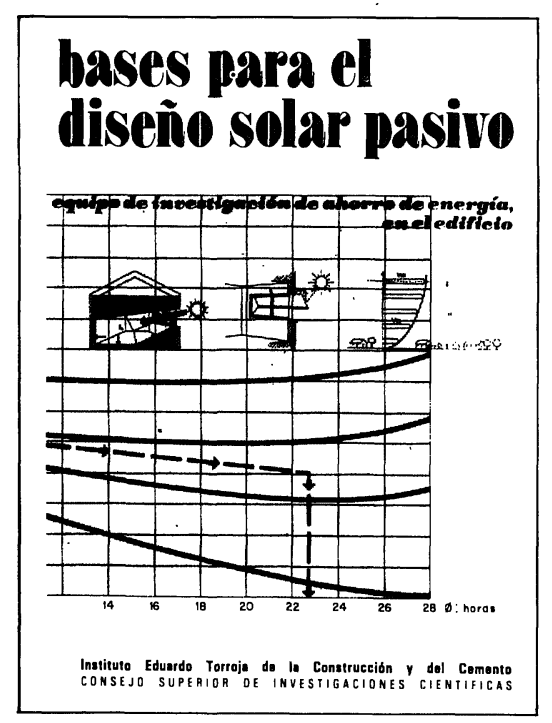

24
Equipo de Ahorro de Energía en el edificio

Dirección y coordinación: Arturo Garcia Arroyo

M. ${ }^{a}$ José Escorihuela José Luis Esteban José Miguel Frutos Manuel Olaya Bernardo Torroja
Las dificultades de suministro y el alto coste de los productos energéticos convencionales han despertado la atención de los usuarios técnicos e industriales de la edificación hacia los procedimientos y sistemas en que se basa el aprovechamiento de otras fuentes alternativas de energia, principaimente la solar. Esto ha generado un rápido desarrollo industrial ha generado un rapido desarrollo industrial $y$ comercial que, en opinion de los autores de este libro, arrastran los siguientes defectos: un mimético tecnologismo respecto de los sistemas convencionales que violenta las pe culiaridades de la energia solar (baja densidad y variabilidad en el tiempol, y una escasa selectividad en la aplicación de los sistemas y procedimientos pasivos dando origen a un ecumenismo arquitectónico solar, al margen de las condiciones climáticas y funcionales específicas de cada caso y lugar.

En este libro, utilizando criterios y metodología pedagógicos, se dan los fundamentos e instrumentos teórico-prácticos necesarios para el planteamiento de todo proyecto arquitectónico solar pasivo, de acuerdo con los principios éticos y económicos de conservación y ahorro de energía. Es decir: respeto de los presupuestos bioclimáticos, búsqueda de la máxima captación y acumulación de la radiación solar, y esmero en el aislamiento térmico de los cerramientos.

Un volumen encuadernado en cartulina ibiza plastificada, a cinco colores, de $16 \times 23 \mathrm{~cm}$, compuesto de 216 páginas, 217 figuras, 87 gráficos, 19 tablas y 10 cuadros.

Madrid, 1983. Precios: España 2.100 ptas.; 30 \$ USA. 